\title{
Preparation and Evaluation of Solid-Self-Emulsifying Drug Delivery System Containing Paclitaxel for Lymphatic Delivery
}

\author{
Hea-Young Cho, ${ }^{1}$ Jun-Hyuk Kang, ${ }^{2}$ Lien Ngo, ${ }^{2}$ Phuong Tran, ${ }^{2}$ and Yong-Bok Lee ${ }^{2}$ \\ ${ }^{1}$ College of Pharmacy, CHA University, 335 Pangyo-ro, Bungdang-gu, Seongnam-si, Gyeonggi-do 13488, Republic of Korea \\ ${ }^{2}$ College of Pharmacy, Chonnam National University, 77 Yongbong-ro, Buk-gu, Gwangju 61186, Republic of Korea \\ Correspondence should be addressed to Yong-Bok Lee; leeyb@chonnam.ac.kr
}

Received 5 February 2016; Revised 22 April 2016; Accepted 5 May 2016

Academic Editor: Jianxun Ding

Copyright (c) 2016 Hea-Young Cho et al. This is an open access article distributed under the Creative Commons Attribution License, which permits unrestricted use, distribution, and reproduction in any medium, provided the original work is properly cited.

\begin{abstract}
Solid-self-emulsifying drug delivery system (S-SEDDS) of paclitaxel (Ptx) was developed by the spray drying method with the purpose of improving the low bioavailability (BA) of Ptx. 10\% oil (ethyl oleate), $80 \%$ surfactant mixture (Tween $80:$ Carbitol, $90: 10$, $\mathrm{w} / \mathrm{w}$ ), and $10 \%$ cosolvent (PEG 400) were chosen according to their solubilizing capacity. The mean droplet size, zeta potential, and encapsulation efficiency of the prepared S-SEDDS were $16.9 \pm 1.53 \mathrm{~nm}, 12.5 \pm 1.66 \mathrm{mV}$, and $56.2 \pm 8.1 \%$, respectively. In the S-SEDDS, Ptx presents in the form of molecular dispersion in the emulsions or is distributed in an amorphous state or crystalline with very small size. The prepared S-SEDDS formulation showed 70 and $75 \%$ dissolution in 60 and 30 min in dissolution medium pH 1.2 and 6.8, respectively. Significant increase $(P \leq 0.05)$ in the peak concentration $\left(C_{\max }\right)$, the area under the curve $\left(\mathrm{AUC}_{0-\infty}\right)$, and the lymphatic targeting efficiency of Ptx was observed after the oral administration of the Ptx-loaded S-SEDDS to rats (20 mg/kg as Ptx). Our research suggests the prepared Ptx-loaded S-SEDDS can be a good candidate for the enhancement of BA and targeting drug delivery to the lymphatic system of Ptx.
\end{abstract}

\section{Introduction}

Paclitaxel (Ptx) is an anticancer drug that has a diterpenoid pseudoalkaloid structure and is extracted from the bark of Western yew, Taxus brevifolia $[1,2]$. It is active in metastatic breast cancer and is under evaluation for the adjuvant and neoadjuvant treatment of early breast cancer $[3,4]$. It has been approved by the US Food and Drug Administration for the treatment of ovarian and breast cancer, Kaposi's sarcoma, and diverse carcinomas including lung, colon, prostate, head and neck, cervical, and brain [5-7]. Ptx is practically insoluble in water with a very low aqueous solubility $[2,8,9]$. It is soluble in a mixture of Cremophor ${ }^{\circledR} \mathrm{EL}$ and anhydrous ethanol $(50: 50, v / v)[2,10]$. Thereby, the commercial product of Ptx (i.e., Taxol ${ }^{\circledR}$, Paxene ${ }^{\circledR}$ ) is prepared as parenteral formulation with the mixture of Cremophor EL and ethanol (50:50, v/v) as solvent. The form needs to be diluted with saline to give a final concentration of $0.03-0.60 \mathrm{mg} / \mathrm{mL}$ Ptx right before the injection. However, Cremophor EL has been associated with serious side effects and leads to hypersensitivity, nephrotoxicity, and neurotoxicity in many patients $[2,11]$.
In the last years, various efforts have been performed to develop Ptx oral formulation. Oral administration would offer advantages over intravenous infusion such as being more attractive for patients because of its simplicity and would enable the development of chronic treatment schedules resulting in sustained plasma concentrations above a pharmacologically relevant threshold level. However, orally administered Ptx presents a major therapeutic problem, because of low bioavailability (BA) $(<10 \%)$ [12]. This effect is mainly due to its low aqueous solubility and dissolution as well as its affinity for intestinal and liver cytochrome P450 metabolic enzymes (i.e., CYP3A4) and the multidrug efflux transporter P-glycoprotein (P-gp) which is present abundantly in the gastrointestinal tract $[5,12]$. To overcome this problem, various formulations have been studied and developed to enhance the oral BA of Ptx, such as liposome [11, 13-15], microsphere [6, 16], nanocapsule [17], nanoparticle [7, 18-20], nanosponge [12], and combination with P-gp inhibitors [5, 21, 22].

Self-emulsifying drug delivery system (SEDDS) has got much attention of researchers in the last decade. The SEDDS 
is an isotropic mixture of oils and surfactants with or without cosolvents, which spontaneously forms an oil-inwater nanoemulsion upon gentle agitation with water. Upon its introduction into aqueous media, it forms fine oil-in-water emulsions with only gentle agitation such as GI motility, because the free energy required to create a new surface between the oil and water is lower than the entropy change that favors dispersion [23]. In comparison to emulsions, SEDDS can overcome the emulsion system's shortcoming in stability, the large volume required, and manufacturing problems associated with their commercial production and can offer an improvement in the rate and extend the absorption by maximizing the drug solubility within the primer absorption site of the gut [24]. Moreover, SEDDS can stimulate the lymphatic transport, because of lipid-based formulation, and lipid may enhance the extent of lymphatic transport and increase the BA directly or indirectly by reducing first-pass metabolism [23, 25-28]. The lymphatic system is a part of the circulatory system and plays a crucial role in the immune system's recognition and response to the disease. It is the primary route for spreading cancer cells or viruses and dissemination infections. Once invaded by cancer cells or viruses, regional lymph nodes act as reservoirs where cancer cells or viruses take root and seed into other parts of the body [29-31]. Thus, the lymphatic system is an important target site for developing new vaccines, anticancer treatments, immunotherapeutic agents, and imaging agents. The key step to successfully prepare a SEDDS is finding a suitable oil phase (oils, surfactants, and/or cosolvents) that has ability to dissolve the drug at required therapeutic concentration [25]. However, SEDDS has high surfactant concentrations which in self-emulsifying formulation irritates the GI tract and volatile cosolvents migrate into the shell of gelatin capsules, resulting in precipitation of the lipophilic drugs.

Solid-SEDDS (S-SEDDS) has been investigated as an alternative approach. S-SEDDS combines the advantages of SEDDS with those of solid dosage forms. A variety of methods such as adsorptions to solid carriers, spray drying, melt extrusion, and nanoparticles technology have been used for the preparation of S-SEDDS [25, 32]. This study aimed to prepare and characterize the S-SEDDS by the spray drying method, because of its simplicity [33] in enhancing drug efficiency and reducing side effects by improving BA and targeting intestinal lymphatic delivery of Ptx. We also evaluated the pharmacokinetic characteristics and lymphatic targeting efficiency of the prepared S-SEDDS in rats.

\section{Materials and Methods}

\subsection{Materials}

2.1.1. Reagents. Ptx was kindly supplied by the Korean Institute of Science and Technology (KIST) (Seoul, Korea). Glimepiride was kindly supplied by Sam Chun Dang Pharm. Co., Ltd. (Seoul, Korea). Olive oil, soybean oil, isopropyl myristate (IPM), oleic acid, polyoxyethylene sorbitan monooleate (Tween 80), Cremophor EL, Carbitol, and dextran were purchased from Sigma-Aldrich (St. Louis, MO, USA). Ethyl oleate and polyethylene glycol 400 (PEG
400) were purchased from Fischer Scientific (Fair Lawn, NJ, USA). Propylene glycol was purchased from Junsei Chemical Co., Ltd. (Tokyo, Japan). Ethylene glycol and ethanol were purchased from Dae-Jung (Incheon, Korea). Aerosil 200 was purchased from Evonik Industry. Normal saline solution (Choongwae Pharma. Co., Seoul, Korea), heparin sodium (25,000 IU/5 mL, Choongwae Pharm. Co., Seoul, Korea), phosphate buffered saline (PBS, pH 7.4, Sigma-Aldrich, St. Louis, MO, USA), 70\% ethanol, and dichloromethane (DCM, Dae-Jung, Incheon, Korea) were used for animal experiments and sample extractions. High-performance liquid chromatography (HPLC) grade water obtained from a Milli-Q water purification system (Millipore Co., Milford, MA, USA) was used throughout the study except HPLC assay. HPLC grade acetonitrile and water (Fischer Scientific, Fair Lawn, NJ, USA) were used for HPLC assay. All other chemicals and solvents were of analytical grade or highest quality available.

2.1.2. Instruments. Chemical balance (EL204-IC, MettlerToledo, Greifensee, Switzerland), vortex mixer (G560, Scientific Industries Inc., Bohemia, NY, USA), bath-type sonicator (Kodo Technical Research Co., Ltd., Hwaseong, Korea), and spray dryer (SD-Basic, Lab-Plant UK Ltd., Filey, North Yorkshire, UK) were used for preparation of S-SEDDS. Particle size analyzer (Scatteroscope-I, Qudix, Seoul, Korea), zeta potential analyzer (ELS-8000, OTSUKA Electronics, Osaka, Japan), shaking incubator (BS-11, Jeio Tech Co., Ltd., Daejeon, Korea), differential scanning calorimeter (DSC823e, Mettler-Toledo, Greifensee, Switzerland), and X-ray diffractometer (X'Pert PRO Multipurpose X-Ray Diffractometer, PANalytical, Almelo, Netherland) were used for the evaluation of the prepared S-SEDDS. For animal experiments the following instruments were used: $\mathrm{pH}$ meter (SevenEasy, Mettler-Toledo, Greifensee, Switzerland), homogenizer (IKA-WERKE, KGD-79219, GmbH \& Co., Staufen, Germany), deep-freezer (DF9014, Il-Shin Lab., Seoul, Korea), centrifugal evaporator (Model CVE-200D, EYELA, Tokyo Rikakikai Co., Ltd., Tokyo, Japan), centrifuge (Model 5415C, Brinkmman Instruments Inc., Westbury, NY, USA), Vacutainer $^{\circledR}($ K3 EDTA, $13 \times 75$ mm, Becton Dickinson, Meylan, UK), and polyethylene tube (PE-50, Intramedic ${ }^{\circledR}$, Clay Adams Co., Parsippany, NJ, USA). HPLC system (Shimadzu Corp., Kyoto, Japan) consisted of a pump (Model LC10ADvp), degasser (model DGU-12A), UV detector (model SPD-10Avp), system controller (SCL-10Avp), and Shim-Pack CLC-ODS $(\mathrm{M}) 15 \mathrm{CM}$ column $(150 \times 4.6 \mathrm{~mm}, 5 \mu \mathrm{m}$ particle size).

2.1.3. Experimental Animals. Experimental animals were managed according to the protocol approved by the Ethical Review Committee on Experimental Animals of Chonnam National University, South Korea. Male Sprague-Dawley rats weighing 190-210 g were obtained from Dae Han Biolink (Eumseong, Korea). Animals were housed separately in a cage in a ventilated animal room with controlled temperature $\left(19 \pm 1^{\circ} \mathrm{C}\right)$ and relative humidity $(50 \pm 5 \%)$, kept on $12 \mathrm{~h}$ light/dark cycle, and provided free access to food (Cheil Food and Chemical, Incheon, Korea) and water. Rats weighing 
$\sim 240-280$ g were used. Prior to the test, the rats were fasted overnight and had access to water.

\subsection{Methods}

\subsubsection{Preparation of SEDDS}

(1) Screening of Oil Phase. Suitable oil, surfactants, and cosolvents were identified by determining the solubilization capacities of various oils (olive oil, soybean oil, IPM, ethyl oleate, and oleic acid), surfactants (Carbitol, Cremophor EL, Tween 80, Cremophor RH40, and Solutol HS 15), and cosolvents (PEG 400, ethylene glycol, propylene glycol, and ethanol) for Ptx, respectively. An excess amount of Ptx was added to a cap vial containing $500 \mu \mathrm{L}$ of each oil, surfactant, and cosolvent. After sealing, the mixtures were mixed by vortexing and heated at $40^{\circ} \mathrm{C}$ using a water bath and then kept for 3 days at $37 \pm 1^{\circ} \mathrm{C}$ in a water shaker to reach equilibrium. At that time, after centrifuging at $5,000 \mathrm{rpm}$ for $15 \mathrm{~min}$ to remove the unsolved Ptx, the supernatants were collected and recentrifuged. Each supernatant was diluted with a specific volume of mobile phase and then $20 \mu \mathrm{L}$ was injected into the HPLC system to determine the solubility of Ptx in each vehicle [35]. The chosen oil phase was used for further study.

(2) Surfactant Combination Test. Combination study was conducted to identify the most effective surfactants with respect to the emulsifying ability of soybean oil, IPM, and ethyl oleate. Tween 80 and Carbitol were selected for the combination test based on the results of the screening of oil phase. As known, each material to be emulsified requires a surfactant (or a surfactant mixture) with a specific hydrophilic-lipophilic balance (HLB) number to optimum emulsification. Use of a surfactant that reaches required HLB value of the lipid should yield a stable emulsion with a small and narrow droplet size [36]. The required HLB values of surfactant (surfactant mixture) for soybean oil, IPM, and ethyl oleate were reported to be $\sim 6-7, \sim 10-12$, and $\sim 14-15$, respectively $[37,38]$. Therefore, we mixed these two surfactants (Tween 80 with HLB of 15 and Carbitol with HLB of 4.2) at various weight ratios to reach the required range of HLB value for each of the oils. The optimal oils and corresponding surfactant mixtures were conducted by visual test and droplet size measurement of the resulting dispersions. The percentage amount of Tween 80 was calculated by the following equation $[36,37]$ :

$$
\% \text { Tween } 80=\frac{\text { RHLB }-\mathrm{HLB}_{\text {low }}}{\mathrm{HLB}_{\text {high }}-\mathrm{HLB}_{\text {low }}},
$$

where $\mathrm{HLB}_{\text {high }}$ and $\mathrm{HLB}_{\text {low }}$ are the HLB value of Tween $80(\mathrm{HLB}=15)$ and that of Carbitol (HLB $=4.2)$, respectively. RHLB is required HLB value. The weight ratio of oil : surfactant mixture was fixed at 1:9 based on the property of class III in lipid formulation classification system proposed by Pouton [39].

(3) Examination of Pseudoternary Phase Diagram. Pseudoternary phase diagrams of a mixture containing oil (ethyl oleate and IPM), surfactant mixtures (Tween 80 : Carbitol) at different HLB values, and water were constructed using the water titration method described previously [40, 41]. Briefly, a predetermined amount of oil-surfactant mixture was diluted with a specific volume of deionized water (DIW) dropwise. The ratios of oil-surfactant mixture were varied from 1:9 to $9: 1$ at $10 \%$ increments. Each mixture was titrated with water under constant magnetic stirring to reach equilibrium; then the nature of the resulting emulsions was decided by turbidity and viscosity with the naked eye [42]. The final oil and surfactant mixture was determined by comparison of the emulsion region area in the phase diagrams.

(4) Determination of Optimal Concentration of Cosolvent. PEG 400 was chosen for the test of effect of cosolvent concentration based on the result of evaluation of the solubility test. The effect of PEG 400 concentration on the droplet size in the SEDDS was studied by increasing its concentration from 10 to $40 \%(\mathrm{w} / \mathrm{w})$. The sort and ratio of oil and surfactant mixture were selected based on the previous test results.

(5) Determination of Optimal Concentration of Ptx. Ethyl oleate $(10 \%, w / w)$, Tween 80 : Carbitol $(90: 10,80 \%, w / w)$, and PEG $400(10 \%, \mathrm{w} / \mathrm{w})$ were fixed to make SEDDS based on the previous test results. The optimal concentration of Ptx was determined by measuring the droplet size and drug encapsulation efficiency (EE). Briefly, $0.5,1,2$, and $5 \mathrm{mg}$ of Ptx were added to $100 \mathrm{mg}$ of blank SEDDS in a cap vial and then sonicated at $50^{\circ} \mathrm{C}$ in a bath-type sonicator until the Ptx was completely dissolved in the blank SEDDS. Final formulation was diluted with $100 \mu \mathrm{L}$ of DIW, gently stirred for $10 \mathrm{~min}$, and kept stationary for $2 \mathrm{~h}$ at $37 \pm 1^{\circ} \mathrm{C}$ before the droplet size and EE measurement. To determine the EE, the resulting emulsions were centrifuged at $3,000 \mathrm{rpm}$ for $10 \mathrm{~min}$ to remove undissolved drugs. The supernatants were collected and added into new glass, followed by diluting with a specific volume of mobile phase. $20 \mu \mathrm{L}$ of each sample was injected into the HPLC system for determination. EE was calculated by the following equation:

$$
\begin{aligned}
& \operatorname{EE}\left(\%, \frac{w}{w}\right) \\
&=\frac{\text { weight of drug in SEDDS droplets }}{\text { weight of drug used in preparation of SEDDS }} \\
& \times 100 .
\end{aligned}
$$

2.2.2. Preparation of S-SEDDS. The S-SEDDS was prepared by the spray drying method. In detail, the solubilized liquid SEDDS was atomized into a spray of droplets. The droplets were introduced into a drying chamber, where the volatile phase (e.g., the water contained in an emulsion) evaporated, forming dry particles under controlled temperature and airflow conditions [32]. To determine the optimal method for preparation of the S-SEDDS, $100 \mathrm{mg}$ of each S-SEDDS formulation was dispersed into $10 \mathrm{~mL}$ of DIW by vortexing and incubated for $6 \mathrm{~h}$ at $25^{\circ} \mathrm{C}[43,44]$. The resultant emulsion was tested for droplet size measurement. This result was basic of determining the optimal method for preparation of SSEDDS. 
Aerosil 200 and dextran were tested to determine the optimal solid carrier. In the test, Aerosil 200 (500 mg) or dextran (2000 mg) was suspended in $100 \mathrm{~mL}$ of water. After sonicating at $50^{\circ} \mathrm{C}$ in a bath-type sonicator, $1 \mathrm{~mL}$ of the optimized liquid SEDDS was added, followed by stirring constantly until a good suspension was obtained. The suspension was then spray-dried as previously described to make the SSEDDS formulation [31]. In the case of solvent test, water and ethanol were compared to identify the optimal solvent. Aerosil 200 (500 mg) was suspended in $100 \mathrm{~mL}$ of solvent and followed by the described method to prepare the S-SEDDS formulation. Optimal solid carrier and solvent obtained from these tests were used for further studies. For determining the optimal concentration of solid carrier, various amounts of Aerosil 200 (125, 200, 250, 333, and $500 \mathrm{mg}$ ) were suspended in $100 \mathrm{~mL}$ of water. The S-SEDDS formulation was prepared as previously described.

\subsubsection{Characterization and Evaluation of the Formulation}

(1) Measurement of Droplet Size, Zeta Potential, and Drug Encapsulation Efficiency. The blank liquid SEDDS, blank SSEDDS, and Ptx-loaded S-SEDDS were tested for droplet size, zeta potential, and drug encapsulation efficiency. The mean droplet size and size distribution of the emulsion droplets were measured by the dynamic light scattering (DLS) method at room temperature with a $90^{\circ}$ scattering angle for optimum detection. The zeta potentials were measured by an ELS-8000 zeta potential analyzer to assess the surface charge and the stability of the emulsions. For the test, an aliquot of $10 \mu \mathrm{L}$ of the liquid SEDDS was diluted with $10 \mathrm{~mL}$ of DIW in a cap vial. The samples were gently mixed for $10 \mathrm{~min}$ and then kept stationary at $37 \pm 1^{\circ} \mathrm{C}$ for $1 \mathrm{~h}$. The formulation of the SSEDDS was dispersed in DIW in a volumetric flask to get final concentration of $\sim 1.5 \mathrm{mg} / \mathrm{mL}$. To ensure complete dispersion of the formulation, the volumetric flask was inverted twice. All studies were repeated in five replicates among different batches and the values of $z$-average diameters were used. To determine drug EE, $100 \mu \mathrm{L}$ of the liquid SEDDS was mixed with $0.9 \mathrm{~mL}$ of methanol and vortexed vigorously for $1 \mathrm{~min}$. The solution was then diluted with a specific volume of mobile phase and injected into the HPLC system for determination. The blank liquid SEDDS, blank S-SEDDS, and Ptxloaded S-SEDDS were reconstituted as previously described.

(2) Thermal Analysis and X-Ray Diffractometry (XRD) Analysis. The endothermic melting temperature for Ptx, blank SSEDDS, physical mixture of Ptx/blank S-SEDDS, and Ptxloaded S-SEDDS was determined by DSC 2920. The physical mixture was prepared by mixing well $1.25 \mathrm{~g}$ of the blank $\mathrm{S}$ SEDDS and $10 \mathrm{mg}$ of Ptx using mortar and pestle (to make a similar ratio of Ptx in the physical mixture to that in the Ptxloaded S-SEDDS). Samples were scanned from 30 to $280^{\circ} \mathrm{C}$ at a rate of $10^{\circ} \mathrm{C} / \mathrm{min}$. In all the cases, an empty pan was used as the reference. XRD patterns of blank S-SEDDS and Ptx-loaded S-SEDDS were recorded using an X'Pert PRO Multipurpose X-Ray Diffractometer equipped with $\mathrm{CuK} \alpha$ radiation $(40 \mathrm{kV}, 20 \mathrm{~mA})$. The $2 \theta$ scanning range was varied from 2 to $100^{\circ}$.
(3) In Vitro Release Studies. The Ptx-loaded S-SEDDS was evaluated for in vitro release using the United States Pharmacopoeia paddle method at $37 \pm 0.5^{\circ} \mathrm{C}$ at $100 \mathrm{rpm}$ in buffer at $\mathrm{pH}$ 1.2 and 6.8. The S-SEDDS was filled in a hard gelatin capsule. Each sample was placed in a dialysis tube (MWCO: 12,000), which was placed in a $50 \mathrm{~mL}$ screw-capped Falcon tube with $10 \mathrm{~mL}$ of dissolution medium. During the study, $1 \mathrm{~mL}$ of each sample was withdrawn at the predetermined time intervals of $10,20,30,45$, and $60 \mathrm{~min}$ and replaced with fresh buffer. The samples were centrifuged at 3,000 rpm for $10 \mathrm{~min}$, and the drug concentration was determined by HPLC.

(4) In Vivo Studies. The femoral artery of rats was cannulated with a PE-50 polyethylene tube under light ether anesthesia. The cannulated rats were kept in restraining cages under normal housing conditions for $\sim 1-2 \mathrm{~h}$ until they recovered from the anesthesia prior to the experiments. The rats were divided into two groups (five rats per group): (1) Ptx solution diluted with $1: 1$ blend of Cremophor EL and ethanol $(6 \mathrm{mg} / \mathrm{mL})[22$, 45,46 ] and (2) Ptx-loaded S-SEDDS. A single dose $(20 \mathrm{mg} / \mathrm{kg}$ of Ptx) of each formulation was orally administered to rats at the same time. At the predetermined time intervals $(0.5,1,1.5$, $2,4,6,8,12$, and $24 \mathrm{~h}$ ), whole blood samples were withdrawn from the femoral artery into Vacutainer tubes with EDTA. The blood samples were then centrifuged (3,000 rpm, $10 \mathrm{~min}$ ) immediately, and plasma was transferred and stored at $-80^{\circ} \mathrm{C}$ until assay. Moreover, for the determination of the targeted lymphatic delivery of Ptx, the rats were also divided into two groups and given each formulation as mentioned above. At $4 \mathrm{~h}$ after the administration, whole blood was taken from the abdominal aorta, and mesenteric and axillary lymph nodes were isolated and weighed [47-49]. These lymph node samples were suspended by homogenization for $1 \mathrm{~min}$ in PBS ( $\mathrm{pH} 7.4$ ) to yield a final concentration of $25 \mathrm{mg} / \mathrm{mL}$ in the suspension. The samples were stored at $-80^{\circ} \mathrm{C}$ until assay.

(5) Determination of Ptx in Rat Plasma and Lymph Node Suspension. The plasma concentration and lymph node suspension of Ptx were determined by HPLC assay following literature method [50-53] with some modifications. The chromatographic column used was Shim-Pack column CLCODS $(\mathrm{M}) 15 \mathrm{CM}(150 \times 4.6 \mathrm{~mm}, 5 \mu \mathrm{m}$ particle size $)$. The mobile phase consisted of acetonitrile: water $(50: 50, \mathrm{w} / \mathrm{w})$, and the flow rate was set at $1 \mathrm{~mL} / \mathrm{min}$. The quantity of Ptx was measured by the UV absorbance at the wavelength of $227 \mathrm{~nm}$. The stock solutions of Ptx and the internal standard (I.S., glimepiride) were prepared at $1 \mathrm{mg} / \mathrm{mL}$ in methanol and stored at $4^{\circ} \mathrm{C}$. Calibration standard samples were prepared by spiking $10 \mu \mathrm{L}$ aliquot of Ptx working solutions into $90 \mu \mathrm{L}$ of blank rat plasma or lymph node suspension to give the final concentrations of Ptx at 10, 20, 50, 100, 200, 500, and $1000 \mathrm{ng} / \mathrm{mL}$. The calibration curves were obtained by plotting the peak-area ratio of the analyte to I.S. against the concentration of Ptx. These samples were treated as the real rat plasma and lymph node suspension samples. Liquid-liquid extraction method was used for the extraction of Ptx from the rat plasma and lymph node suspension samples. In sum, $100 \mu \mathrm{L}$ of each sample was placed in an Eppendorf tube, followed by adding $10 \mu \mathrm{L}$ of I.S. (glimepiride 
in methanol, $5 \mu \mathrm{g} / \mathrm{mL}$ ). After vortexing for $30 \mathrm{~s}, 2 \mathrm{~mL}$ of DCM was added and vortexed for 2 min for extraction. After centrifuging at 3,000 rpm for $10 \mathrm{~min}$, the upper layer was aspirated and $1.5 \mathrm{~mL}$ of the lower organic layer was transferred to a polypropylene tube and evaporated at room temperature under vacuum. The residue was reconstituted in $100 \mu \mathrm{L}$ of mobile phase, and $20 \mu \mathrm{L}$ was injected into the HPLC system for determination.

(6) Pharmacokinetic Analysis and Lymphatic Delivery Evaluation. The pharmacokinetic parameters such as the area under the plasma concentration-time curve $\left(\mathrm{AUC}_{0-\infty}\right)$, time to peak plasma concentration $\left(T_{\max }\right)$, and peak concentration $\left(C_{\max }\right)$ associated with the oral administration were estimated by the noncompartment methods using a WinNonlin ${ }^{\mathrm{TM}}$ program $[54,55]$. Moreover, the targeting efficiency of Ptx to the lymphatic system was estimated as the ratio of Ptx concentration in lymph nodes to the concentration in rat plasma at $4 \mathrm{~h}$ after the oral administration of each formulation [55].

2.2.4. Statistical Evaluation. All the calculated values are expressed as mean $\pm \mathrm{SD}$. All the data were analyzed for statistical significance by Student's $t$-test with $P \leq 0.05$ indicating a significant difference.

\section{Results and Discussion}

\subsection{Preparation of SEDDS}

3.1.1. Screening of Oil Phase. The oil represents one of the most important excipients in the SEDDS formulation because it can solubilize considerable amount of the lipophilic drug and increase the fraction of the drug transported via the intestinal lymphatic system. In general, modified mediumchain triglyceride (MCT) oils, with varying degrees of saturation or hydrolysis, have been used widely for the design of SEDDS, because the solvent capacity of MCT for lipophilic drugs is higher than that of long chain triglyceride (LCT) and it does not oxidize [24, 56]. Moreover, because the junctions of the endothelial cells forming walls of lymphatic capillaries are larger than those of blood capillaries and the rate of fluid flows in the portal blood is $\sim 500$ times higher than that of the intestinal lymph [57], the vehicles with small size enough to penetrate blood capillaries are not easily absorbed to the lymph. Thereby, fatty acids with long chain length about 14 or greater, which can produce more hydrophobic and larger chylomicron in enterocytes, are preferred for effective lymphatic drug transport than fatty acids having short carbon chain $[58,59]$. Furthermore, the production of an optimum SEDDS requires relatively high concentrations (generally more than $30 \% \mathrm{w} / \mathrm{w}$ ) of surfactants to form a stable SEDDS [60]. The addition of cosolvents aids in enabling the dissolution of large amounts of hydrophilic surfactants and also contributes to the improvement of lipophilic drug solubility in the lipid vehicle [60]. In this study, we screened various organic solvents, including ethanol, PEG 400, ethylene glycol, and propylene glycol because they are suitable for oral administration.
TABLE 1: Solubility of Ptx in various oils, surfactants, and cosolvents.

\begin{tabular}{lc}
\hline & Solubility $^{\#}(\mathrm{mg} / \mathrm{mL})$ \\
\hline Oils & \\
Olive oil & $1.00 \pm 0.14$ \\
Soybean oil & $2.29 \pm 0.01$ \\
IPM (isopropyl myristate) & $2.46 \pm 0.03$ \\
Ethyl oleate & $2.88 \pm 0.08$ \\
Oleic acid & $0.38 \pm 0.07$ \\
\hline Surfactants & \\
Carbitol & $70.09 \pm 1.02$ \\
Cremophor ${ }^{\circledR}$ EL & $20.13 \pm 0.42$ \\
Tween 80 & $52.64 \pm 0.77$ \\
Cremophor RH40* & $30.52 \pm 1.67$ \\
Solutol HS $15^{*}$ & $20.74 \pm 1.81$ \\
\hline Cosolvents & \\
PEG 400 & $43.28 \pm 0.08$ \\
Ethylene glycol & $9.62 \pm 0.25$ \\
Propylene glycol & $14.35 \pm 0.13$ \\
Ethanol & $32.27 \pm 0.29$ \\
\hline
\end{tabular}

*From Sun et al. [34]

${ }^{\#}$ Mean \pm SD $(n=5)$.

The solubility of Ptx in various oils, surfactants, and cosolvents is shown in Table 1. Optimal oil and surfactants are considered as having good solubilization capacity, because the property of the SEDDS components for dug is important to achieve the optimum drug loading, prevent precipitation from SEDDS during the storage and in vivo dilution, and achieve clear and monophasic formulation at ambient temperature. There were no significant differences among five chosen oils in terms of the solubility of Ptx, except for olive oil and oleic acid.

From the result, soybean oil, IPM, and ethyl oleate, Tween $80($ HLB $=15)$ and Carbitol (HLB $=4.2$ ), and PEG 400 were selected as oil, surfactants, and cosolvent, respectively, because of the highest solubilization capillary for Ptx.

3.1.2. Surfactant Combination Test. HLB refers to the relative attraction of a surfactant of emulsifier for water and oil. The efficiency of self-emulsification is much related to the HLB of the surfactant [41]. Normally, surfactants with higher HLB value show a high efficiency on SEDDS [35]. However, low HLB surfactants may also be an important component of oral lipid-based formulation by behaving as a coupling agent for the high HLB surfactants and the lipophilic solvent components, as well as contributing to solubilization by remaining associated with the lipophilic solvent after dispersion. Moreover, using a blend of high and low HLB surfactants may also lead to more rapid dispersion and finer emulsion droplet size upon the addition to an aqueous phase [39, 40, 56-58, 6163]. Thus, in this study, we mixed a surfactant with high HLB value (Tween $80($ HLB $=15)$ ) with a surfactant with low HLB value (Carbitol (HLB $=4.2)$ ) to identify the most effective combination emulsifying with three chosen oils. The size of the emulsion droplets decreased as the HLB value of surfactant mixture reached the required HLB (Table 2). In 
TABLE 2: The results of droplet size measurement in surfactant combination tests ${ }^{\#}$.

\begin{tabular}{|c|c|c|c|c|c|}
\hline \multirow[t]{2}{*}{ Oil } & \multicolumn{2}{|c|}{ Ratio (\%) } & \multirow[t]{2}{*}{ HLB } & \multicolumn{2}{|c|}{$\begin{array}{l}\text { Droplet size } \\
(\mathrm{nm})\end{array}$} \\
\hline & Tween $80(\mathrm{HLB}=15)$ & Carbitol $(\mathrm{HLB}=4.2)$ & & Mean & $\mathrm{SD}$ \\
\hline \multirow{3}{*}{$\begin{array}{l}\text { Soybean oil } \\
\text { (required HLB, 6 7) }\end{array}$} & 15 & 85 & 5.8 & 316 & 33.9 \\
\hline & 20 & 80 & 6.4 & 277 & 2.49 \\
\hline & 25 & 75 & 6.9 & 473 & 182 \\
\hline \multirow{3}{*}{$\begin{array}{l}\text { Ethyl oleate } \\
\text { (required HLB, 14 15) }\end{array}$} & 90 & 10 & 13.9 & 10.5 & 0.596 \\
\hline & 95 & 5 & 14.5 & 11.1 & 0.205 \\
\hline & 100 & 0 & 15 & 11.5 & 0.807 \\
\hline \multirow{3}{*}{$\begin{array}{l}\text { IPM } \\
\text { (required HLB, 10 12) }\end{array}$} & 60 & 40 & 10.7 & 12.9 & 0.170 \\
\hline & 65 & 35 & 11.2 & 13.1 & 0.125 \\
\hline & 70 & 30 & 11.8 & 13.2 & 0.974 \\
\hline
\end{tabular}

${ }^{\#}$ The weight ratio of oil : surfactant mixture was fixed at 1:9. SD is standard deviation $(n=5)$.

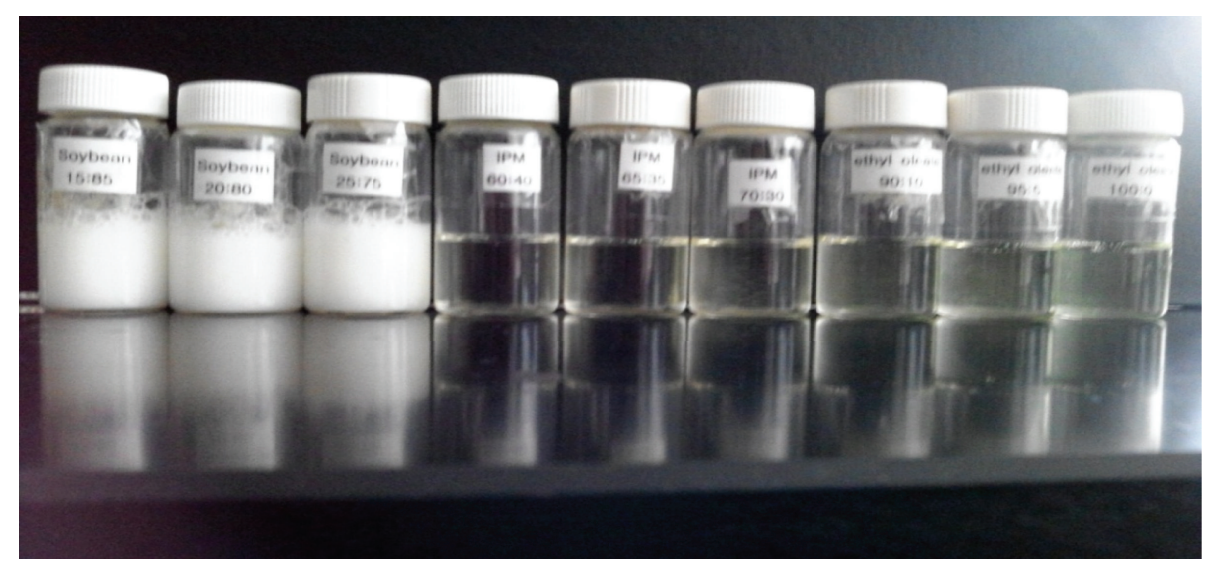

FIGURE 1: The results of visual test in various combination tests.

the case of soybean oil, the smallest size was $277 \pm 2.49 \mathrm{~nm}$ obtained at $20: 80(\mathrm{w} / \mathrm{w})$ ratio of Tween $80:$ Carbitol. In the cases of ethyl oleate (Tween $80:$ Carbitol, $90: 10$, w/w) and IPM (Tween $80:$ Carbitol, $60: 40$ ), the smallest droplet sizes were $2.9 \pm 0.170$ and $10.5 \pm 0.596 \mathrm{~nm}$, respectively. These results show that the combination of Tween 80 and Carbitol had extremely good emulsifying ability, resulting in a fine emulsion in the cases of using ethyl oleate and IPM oil.

The results of the visual test (Figure 1) are parallel to the results of droplet size measurements. The combinations that had a smaller droplet size of $100 \mathrm{~nm}$ or less formed a transparent or bluish emulsion, and this phenomenon was consistent with the features of microemulsion in the literature. Overall, we selected Tween 80 and Carbitol as surfactant mixture for ethyl oleate and IPM (oil) for further studies.

3.1.3. Examination of Pseudoternary Phase Diagram. Drawing of ternary phase diagrams gives an idea about the composition of a selected system and the nature of the resultant dispersions such as phase separation, coarse emulsions, selfnanoemulsification and, hence, assists in selecting optimum formulation [56, 62]. Figure 2(a) shows the phase diagrams of IPM, water, and surfactant mixtures at the weight ratios of
$60: 40(\mathrm{HLB}=10.7), 65: 35(\mathrm{HLB}=11.2)$, and $70: 30(\mathrm{HLB}=$ 11.8) Tween 80 : Carbitol, respectively. Figure 2(b) shows the phase diagrams of ethyl oleate, water, and surfactant mixtures at the weight ratios of $90: 10(\mathrm{HLB}=13.9), 95: 5(\mathrm{HLB}=$ 14.5), and $100: 0(\mathrm{HLB}=15)$ Tween 80 : Carbitol, respectively. Filled circles mean self-emulsifying points, and black areas represent the self-emulsifying regions. In other areas, the compositions showed inverted emulsion, gel-like form, or phase separation. In general, when the oil content in the oil and surfactant mixtures is less than $30 \%$, the condition of the mixtures changed from water-in-oil emulsion to a clear gellike form and then to microemulsion [56]. Otherwise, the dispersions showed phase separation; this result was similar to the results previously studied by Guo and Chu [16]. Our finding showed that IPM + surfactant mixture $(65: 35, \mathrm{w} / \mathrm{w})$ and ethyl oleate + surfactant mixture $(90: 10$, w/w) showed the most self-emulsifying regions (Figure 2). Overall, in contrast to IPM + surfactant mixture $(65: 35, \mathrm{w} / \mathrm{w})$, ethyl oleate + surfactant mixture $(90: 10, \mathrm{w} / \mathrm{w})$ showed finer emulsion in larger self-emulsifying range. These results indicate that ethyl oleate and Tween 80 : Carbitol $(90: 10, \mathrm{w} / \mathrm{w})$ were identified as the optimal oil and surfactant mixture, respectively, for preparing SEDDS. 


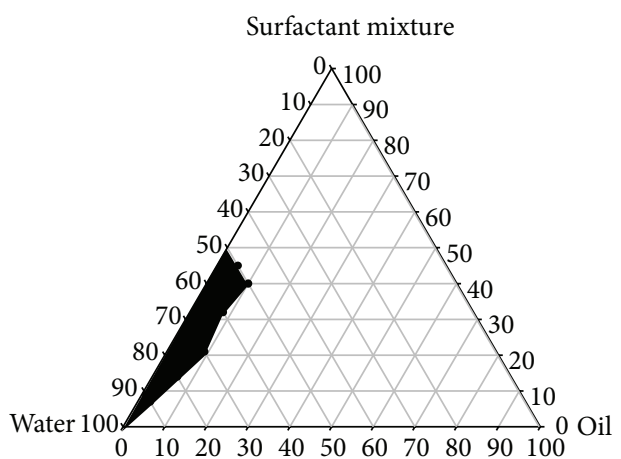

(a1) Surfactant mixture $(60: 40)$

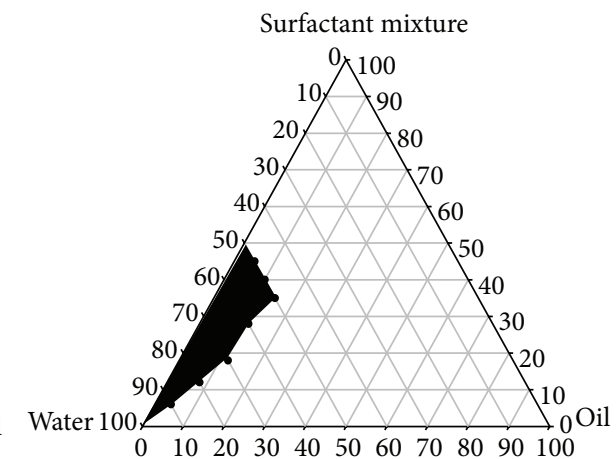

(a2) Surfactant mixture $(65: 35)$

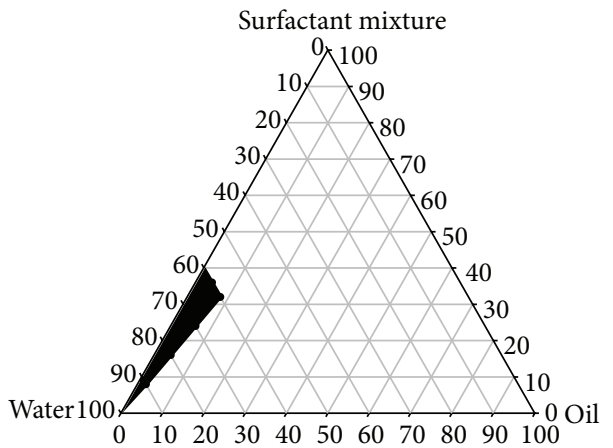

(a3) Surfactant mixture $(70: 30)$

(a)

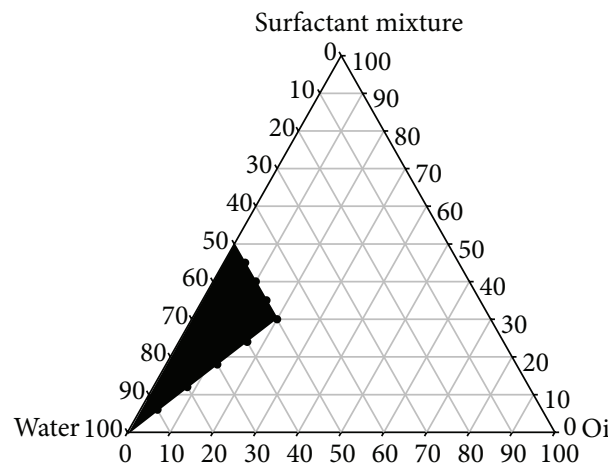

(b1) Surfactant mixture $(90: 10)$

Oil Water 100

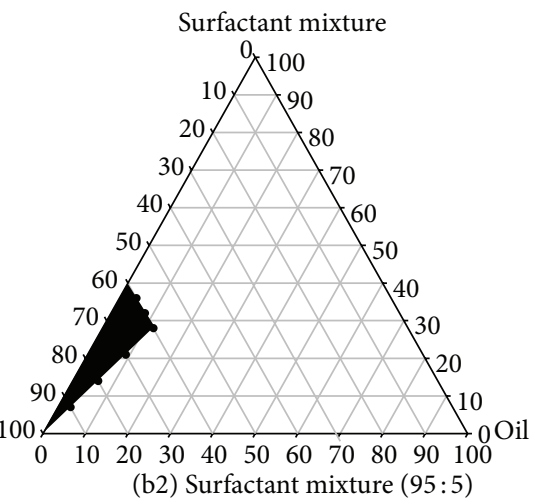

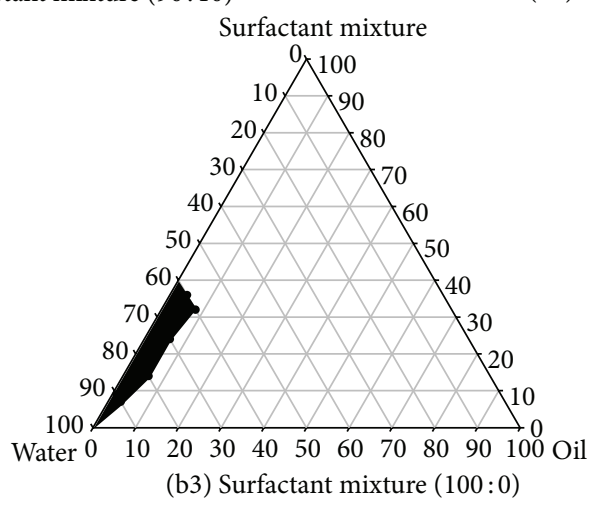

(b)

Figure 2: Pseudoternary phase diagram with surfactant mixture of Tween 80 : Carbitol. Pseudoternary phase diagram for a mixture of (a) IPM, water, and surfactant mixture at (a1) $60: 40(\mathrm{HLB}=10.7)$, (a2) $65: 35(\mathrm{HLB}=11.2)$, and (a3) $70: 30(\mathrm{HLB}=11.8)$ weight ratio of Tween 80: Carbitol and (b) ethyl oleate, water, and surfactant mixture at (b1) $90: 10$ (HLB = 13.9), (b2) $95: 5$ (HLB = 14.5), and (b3) 100:0 (HLB = 15) weight ratio of Tween 80 : Carbitol. Filled circles $(\bullet)$ represent studied points, and black areas represent the self-emulsifying regions. 
TABLE 3: The results of droplet size measurement in effect of cosolvent test ${ }^{\#}$.

\begin{tabular}{lcc}
\hline Cosolvent ratio $(\%, \mathrm{w} / \mathrm{w})$ & Mean $(\mathrm{nm})$ & $\mathrm{SD}(\mathrm{nm})$ \\
\hline 10 & 10.7 & 0.392 \\
20 & 14.1 & 0.544 \\
30 & 17.3 & 1.537 \\
40 & 27.5 & 0.368 \\
\hline
\end{tabular}

${ }^{\#}$ The weight ratio of oil : surfactant mixture was fixed at 1:9. SD is standard deviation $(n=5)$.

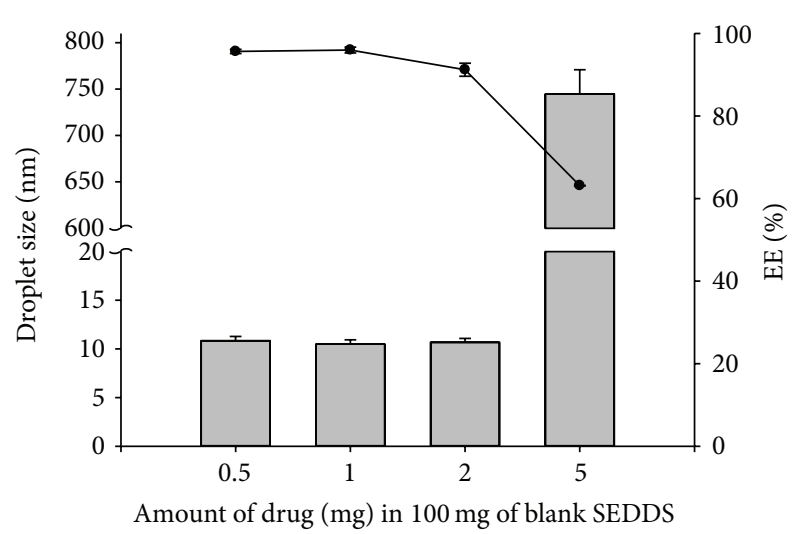

FIGURE 3: Effect of drug incorporation in SEDDS system on mean droplet size $(\boldsymbol{\square})$ and encapsulation efficiency $(\bullet)$. Each value represents the mean $\pm \mathrm{SD}(n=5)$.

3.1.4. Determination of Optimal Concentration of Cosolvent. As known, cosolvents can be powerful solubilizing agents for lipophilic molecules. However, it is important to realize that smaller quantity of cosolvents should be used in SEDDS because larger amounts can cause drug precipitation on dispersion into aqueous phase in the in vivo environment on oral administration [64].

The concentrations of PEG 400 were varied from 10 to $40 \%(w / w)$ to evaluate the effect of cosolvent concentration on the SEDDS droplet size. As shown in Table 3, the mean droplet size of SEDDS increased with increasing PEG 400 concentration in the range of $11-28 \mathrm{~nm}$. The smallest droplet size was $10.7 \pm 0.392 \mathrm{~nm}$ obtained at $10 \%(\mathrm{w} / \mathrm{w})$ of PEG 400. From these results, the optimal concentration was determined at 10\% (w/w) of PEG 400.

3.1.5. Determination of Optimal Concentration of Ptx. The mean sizes and EE were used to evaluate the optimal drug concentration and the effect of drug incorporation on SEDDS. As shown in Figure 3, the mean droplet size was maintained in the range of $\sim 10-15 \mathrm{~nm}$ at $0.5,1$, and $2 \mathrm{mg}$ Ptx but dramatically increased to $\sim 750 \mathrm{~nm}$ at the $5 \mathrm{mg}$ of Ptx incorporation on $100 \mathrm{mg}$ of SEDDS. Moreover, the EE decreased with increasing drug extent. It might be interpreted that the possibility of precipitation increased with increasing drug concentration because the calculated maximum solubility of Ptx in this SEDDS (100 mg) was about $2 \mathrm{mg}$. Several
TABLE 4: The results of droplet size measurement in solid carrier and solvent tests.

\begin{tabular}{lcc}
\hline & Mean $(\mathrm{nm})$ & SD $(\mathrm{nm})$ \\
\hline Solid carrier & & \\
$\quad$ Dextran & 84.1 & 1.77 \\
$\quad$ Aerosil ${ }^{\circledR}$ 200 & 29.9 & 1.15 \\
\hline Solvent & & \\
$\quad$ Ethanol & 457 & 29.1 \\
$\quad$ Water & 29.9 & 1.15 \\
\hline Amount of Aerosil ${ }^{\circledR} 200$ & & \\
$500 \mathrm{mg}$ & 38.03 & 11.43 \\
$333 \mathrm{mg}$ & 30.67 & 6.46 \\
$250 \mathrm{mg}$ & 14.37 & 1.53 \\
$200 \mathrm{mg}$ & 20.73 & 1.47 \\
\hline
\end{tabular}

$\mathrm{SD}$ is standard deviation $(n=5)$.

studies observed similar trends: droplet sizes may increase and EEs may decrease with increasing drug incorporation on SEDDS [24, 27, 40, 59, 61]. Because there was no significant difference between 0.5 and $1 \mathrm{mg}$ of Ptx incorporation on SEDDS with respect to droplet size and EE, the optimal drug concentration was determined at $1 \mathrm{mg}$ of Ptx per $100 \mathrm{mg}$ of blank SEDDS.

In summary, the optimal Ptx-loaded liquid SEDDS formulations were prepared as the following procedure: Ptx $(1 \mathrm{mg})$ was added into $100 \mathrm{mg}$ of the blank SEDDS that contains ethyl oleate (oil, 10\%,w/w), Tween 80 : Carbitol (90:10, w/w) (surfactant mixture, 80\%, w/w), and PEG 400 (cosolvent, 10\%, w/w). The resultant mixture was sonicated at $50^{\circ} \mathrm{C}$ in a bath-type sonicator until a clear solution was obtained (the Ptx was completely dissolved in the blank SEDDS). This liquid SEDDS formulation containing Ptx was used for further studies.

3.2. Preparation of S-SEDDS. Aerosil 200 and dextran (solid carrier) and water and ethanol (solvent) were selected to determine the optimal solid carrier and solvent for preparing S-SEDDS. The results of droplet size are shown in Table 4. There was a significant difference in the size of emulsion droplets between using Aerosil 200 and dextran as the solid carrier with the droplet size of $29.9 \pm 1.15 \mathrm{~nm}$ and $84.1 \pm 1.77 \mathrm{~nm}$, respectively. A significant difference was also observed in the size of emulsion droplet using water and ethanol as the solvent with droplet size of $29.9 \pm 1.15 \mathrm{~nm}$ and $457 \pm 29.1 \mathrm{~nm}$, respectively (Table 4 ). Based on these results, Aerosil 200 and water were chosen for further studies. Table 4 also shows the droplet size of S-SEDDS for the test determining the optimal amount of solid carrier (Aerosil 200). As shown, the amount of the solid carrier (Aerosil 200) affects the droplet size of the resultant dispersion. The droplet size of the S-SEDDS may increase with increasing Aerosil 200 amount over a range of 250 to $500 \mathrm{mg}$. But, the mean droplet size of S-SEDDS with $200 \mathrm{mg}$ of Aerosil 200 was larger than that of S-SEDDS with $250 \mathrm{mg}$ of Aerosil 200. And the formulation prepared with $125 \mathrm{mg}$ of Aerosil $200 \mathrm{did}$ not form 


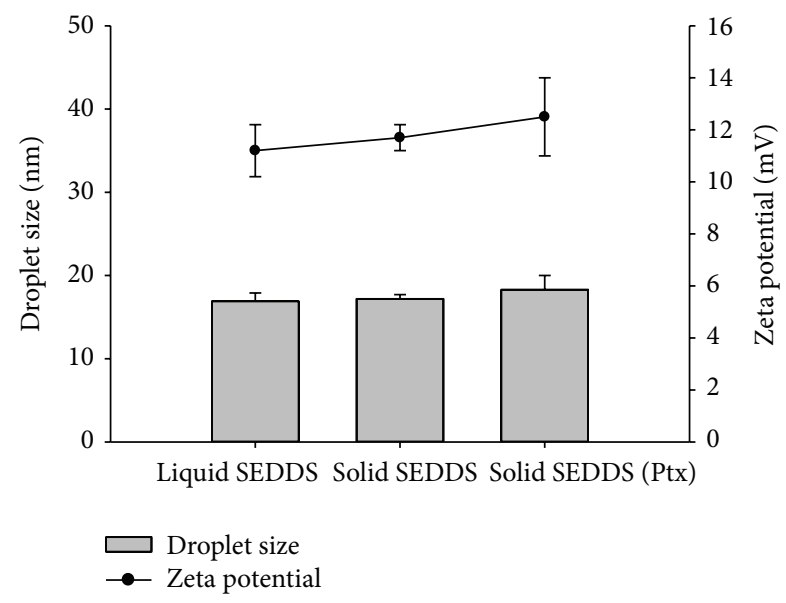

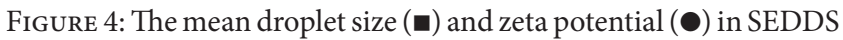
and S-SEDDS system. Each value represents the mean \pm SD $(n=5)$.

the S-SEDDS. These phenomena suggested with less than $125 \mathrm{mg}$ of Aerosil 200 that the S-SEDDS could not be made because of the shortage of solid carrier; over a range between required amount to form solid formulation and $250 \mathrm{mg}$ of Aerosil 200, the droplet size of the S-SEDDS may not increase with increasing Aerosil 200 amount; but with more than $250 \mathrm{mg}$ of Aerosil 200, there was a trend that the droplet size increases with increasing Aerosil 200. Based on these results, an amount of $250 \mathrm{mg}$ of Aerosil 200 was chosen for preparing optimal S-SEDDS.

In summary, the optimal S-SEDDS was prepared as follows: Aerosil $200(250 \mathrm{mg})$ was suspended in $100 \mathrm{~mL}$ of water. After sonicating at $50^{\circ} \mathrm{C}$ in a bath-type sonicator, $1 \mathrm{~mL}$ of the optimized liquid SEDDS was added and followed by stirring constantly until a good suspension was obtained. The suspension was then spray-dried as previously described.

\subsection{Characterization and Evaluation of the Formulation}

3.3.1. Measurement of Droplet Size, Zeta Potential, and Drug Encapsulation Efficiency. The mean droplet size and zeta potential of Ptx-loaded S-SEDDS were not significantly different from those of the blank liquid SEDDS droplet and blank S-SEDDS (Figure 4). In detail, the mean sizes of liquid SEDDS, blank S-SEDDS, and Ptx-loaded S-SEDDS droplets in DIW were $15.6 \pm 0.395,16.9 \pm 1.53$, and $18.4 \pm 0.912 \mathrm{~nm}$, respectively. The zeta potential of liquid SEDDS, blank SSEDDS, and Ptx-loaded S-SEDDS droplets in DIW was $11.1 \pm$ $0.965,11.4 \pm 0.587$, and $12.5 \pm 1.66 \mathrm{mV}$, respectively. From these results, we expected that the prepared Ptx-loaded SSEDDS can be a good candidate to improve the BA and biocompatibility by targeting Ptx to the lymphatic system.

3.3.2. Thermal Analysis and X-Ray Diffractometry (XRD) Analyses. The physical status of Ptx in the prepared S-SEDDS was investigated since it would have an important influence on the in vitro and in vivo release characteristics. The DSC thermograms for Ptx, the blank S-SEDDS, physical mixture

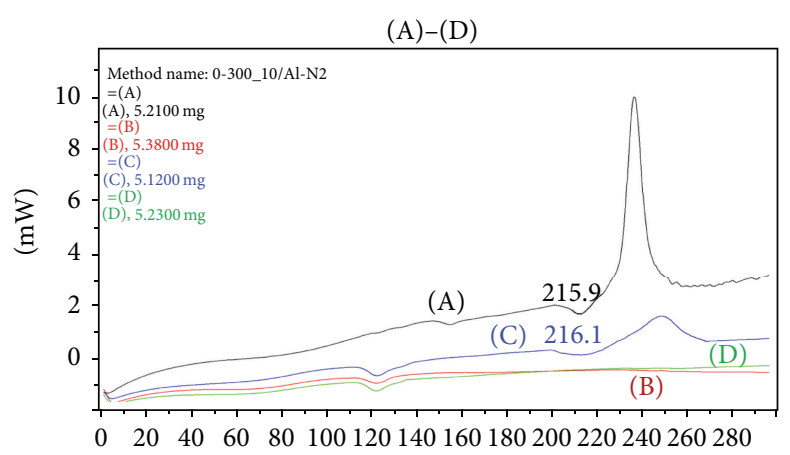

$\left({ }^{\circ} \mathrm{C}\right)$

Lab: METTLER

$\mathrm{STAR}^{\star}$ SW 9.10

FIgure 5: DSC thermograms of (A) Ptx, (B) blank S-SEDDS, (C) physical mixture of Ptx/blank S-SEDDS, and (D) Ptx-loaded SSEDDS.

of Ptx/blank S-SEDDS, and Ptx-loaded S-SEDDS are shown in Figure 5 (the DSC thermograms). Pure Ptx showed a sharp endothermic peak corresponding to a melting point of $220^{\circ} \mathrm{C}$ (curve (A)). This value was consistent with reported melting point of Ptx in previous literature [65-67]. A similar endothermic peak for Ptx was observed in the physical mixture of Ptx/blank S-SEDDS (curve (C)). In contrast, such peaks were not found in the blank S-SEDDS (curve (B)) and in the Ptx-loaded S-SEDDS (curve (D)). The results indicated that the drug would be either molecularly dispersed in the SSEDDS formulation or distributed in an amorphous state or crystalline with very small size.

This suggestion was also confirmed by the XRD study. As known, the intensity of the XRD peak depends on the crystal size. Ptx powder exhibited several intense diffraction peaks [68]. However, these peaks were not observed in the XRD patterns of blank S-SEDDS (Figure 6(a)) and Ptx-loaded SSEDDS (Figure 6(b)).

3.3.3. In Vitro Release Studies. As mentioned above, in the SEDDS, the free energy required to create a new surface between the oil and water is very low. It is suggested that the oil/surfactant/cosolvent and water phases effectively swell, decrease the droplet size, and eventually increase the release rate. In vitro dissolution profiles of Ptx in $\mathrm{pH} 1.2$ and 6.8 from the Ptx-loaded S-SEDDS are displayed in Figure 7. The release ratios of Ptx from the Ptx-loaded S-SEDDS in pH 1.2 and 6.8 reached 70 and $75 \%$ within 60 and $30 \mathrm{~min}$, respectively. Aerosil 200 is hydrophilic fumed silica and is dispersed easily in both the two buffers. Thereby, it seems to have no effect on the release rate of Ptx from the formulation. Additionally, because Ptx is a weak base $(\mathrm{pKa}=10.36)$, its solubility increases with decreasing the $\mathrm{pH}$; a higher solubility can be obtained in $\mathrm{pH} 1.2$ buffer than in $\mathrm{pH} 6.8$ buffer. But, as shown in Figure 7, the release rate of Ptx in $\mathrm{pH} 6.8$ buffer was higher and faster than that in $\mathrm{pH} 1.2$ buffer, especially within the first $30 \mathrm{~min}$. This inverse phenomenon may be attributed to the effect of environmental $\mathrm{pH}$ on the hard gelatin capsule and the dialysis membrane for a short period of time (30 min) 


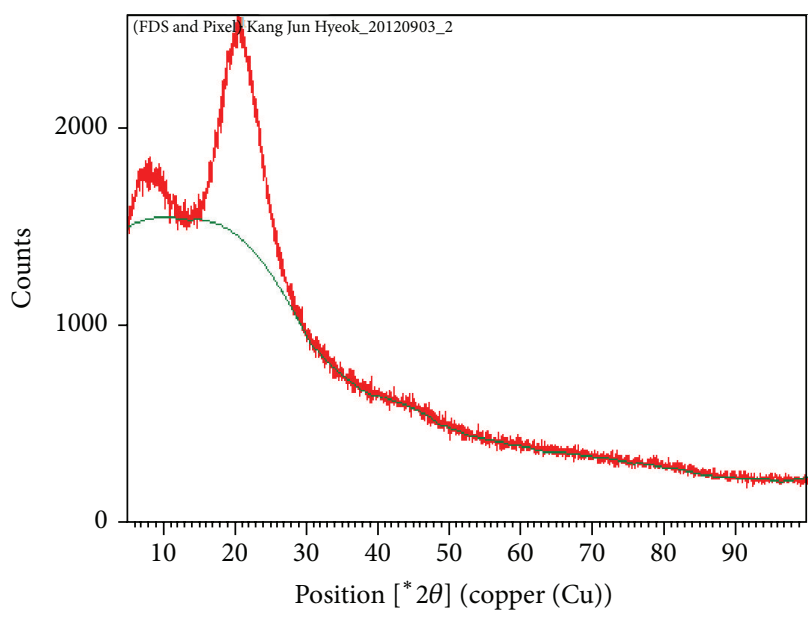

(a)

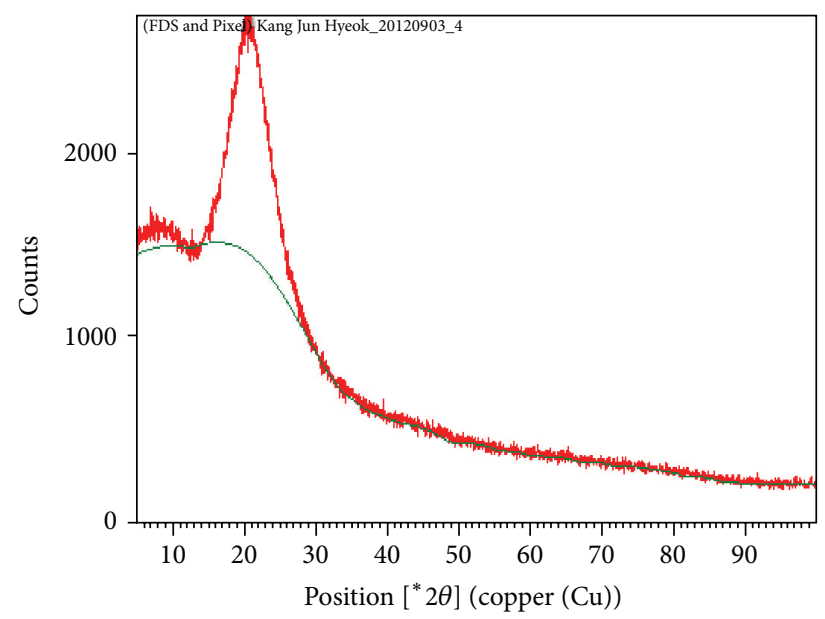

(b)

FIgURE 6: XRD patterns of (a) blank S-SEDDS and (b) Ptx-loaded S-SEDDS.

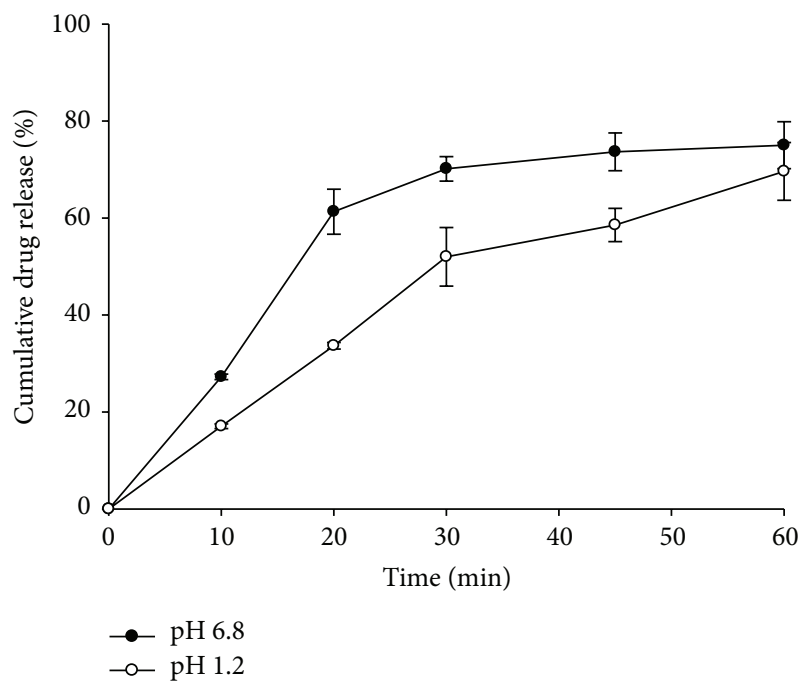

FIGURE 7: In vitro dissolution profiles of Ptx from the S-SEDDS in pH 6.8 and 1.2 at $37 \pm 0.5^{\circ} \mathrm{C}$. Each value represents the mean $\pm \mathrm{SD}$ $(n=5)$.

which indirectly affects the release rate of Ptx from the SSEDDS formulation.

More importantly, according to the previous report on dissolution profiles of Ptx powder, it took $72 \mathrm{~h}$ to release 3.2\% of Ptx in pH 6.8 buffer [14]. In comparison to the report, a dramatic increase in dissolution of Ptx was observed in the Ptx-loaded S-SEDDS. This effect may be due to the small droplet size of the formulation resulting in a higher surface area of drug exposed to the dissolution media which permits a faster rate of drug release into aqueous phase. Additionally, the effect was attributed to the improvement of drug dissolution by the surfactant mixture (Tween 80 :Carbitol) and Aerosil 200. The study ensured that the S-SEDDS preserved the improvement of in vitro dissolution of liquid SEDDS.

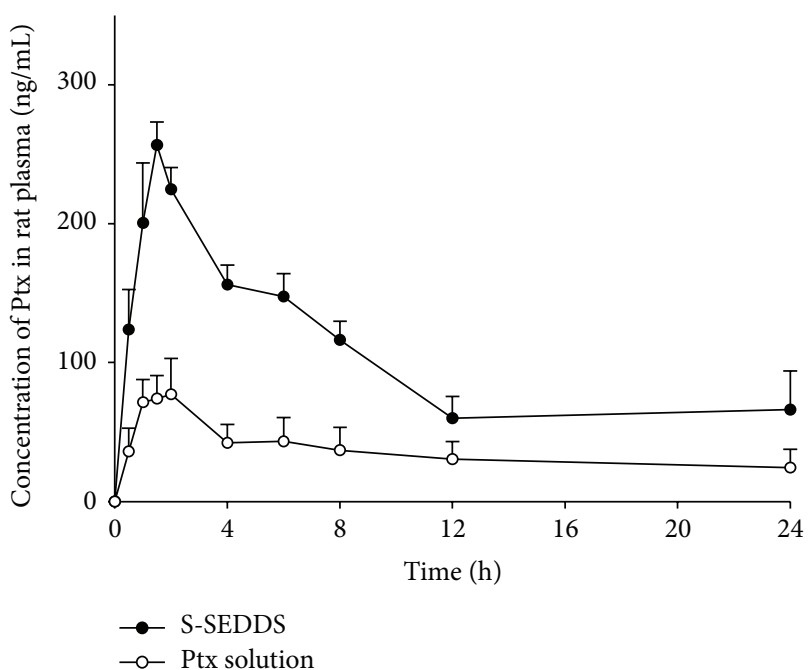

Figure 8: Rat plasma concentration-time profiles of Ptx after oral administration $(20 \mathrm{mg} / \mathrm{kg})$ of the Ptx-loaded S-SEDDS and Ptx solution to rats. Each value represents the mean $\pm \operatorname{SD}(n=5)$.

3.3.4. Pharmacokinetic Analysis and Lymphatic Delivery Evaluation. Figure 8 shows the mean rat plasma concentrationtime profiles of Ptx after the oral administration of Ptxloaded S-SEDDS and reference solution $(20 \mathrm{mg} / \mathrm{kg}$ as Ptx, Cremophor EL : ethanol $=1: 1$ ), respectively. Table 5 lists the pharmacokinetic parameters obtained by the noncompartmental methods using WinNonlin. After the oral administration, the pharmacokinetic parameters related with BA such as $\mathrm{AUC}_{0-\infty}$ and $C_{\max }$ of the Ptx-loaded S-SEDDS $(3308.5 \pm 486.2 \mathrm{ng} \cdot \mathrm{hr} / \mathrm{mL}$ and $259.5 \pm 7.5 \mathrm{ng} / \mathrm{mL}$, resp.) showed significant differences $(P \leq 0.05)$ in comparison to those of the reference solution $(1816.5 \pm 206.4 \mathrm{ng} \cdot \mathrm{h} / \mathrm{mL}$ and $84.6 \pm$ $4.1 \mathrm{ng} / \mathrm{mL}$, resp.). $\mathrm{AUC}_{0-\infty}$ and $C_{\max }$ of the Ptx-loaded SSEDDS were 1.8 and 3.0 times higher than those of the reference solution. The concentrations of Ptx in the mesenteric 


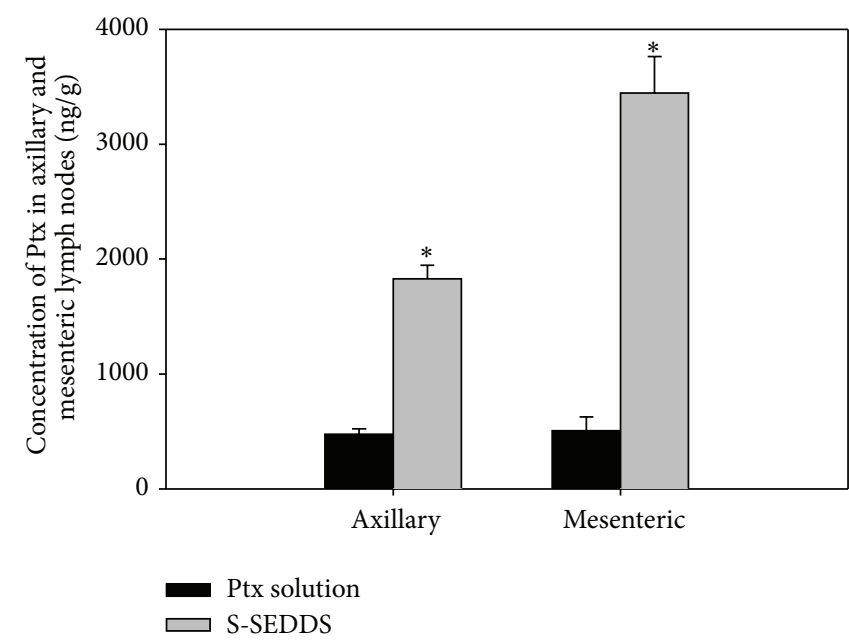

(a)

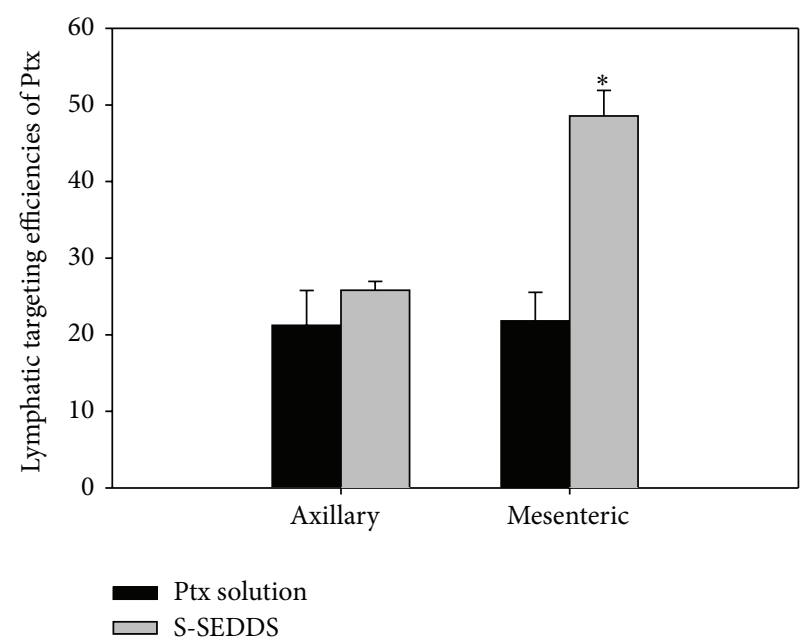

(b)

Figure 9: (a) Concentration of Ptx in mesenteric and axillary lymph nodes at $4 \mathrm{~h}$ after the oral administration of Ptx solution and Ptxloaded S-SEDDS to rats. (b) Lymphatic targeting efficiencies of Ptx in mesenteric and axillary lymph nodes at $4 \mathrm{~h}$ after oral administration $(20 \mathrm{mg} / \mathrm{kg})$ of the Ptx-loaded S-SEDDS and Ptx solution to rats. Vertical bar represents the mean \pm SD $(n=5) .{ }^{*} P \leq 0.05$ between the S-SEDDS formulation and paclitaxel solution.

TABLE 5: Pharmacokinetic parameters of Ptx after the oral administration $(20 \mathrm{mg} / \mathrm{kg})$ of the Ptx reference and Ptx-loaded S-SEDDS in rats $(n=5)$.

\begin{tabular}{lcc}
\hline \multirow{2}{*}{ Parameters } & \multicolumn{2}{c}{ Oral administration } \\
& Ptx solution & S-SEDDS \\
\hline$C_{\max }(\mathrm{ng} / \mathrm{mL})^{\#}$ & $84.6 \pm 4.1$ & $259.5 \pm 7.5$ \\
$T_{\max }(\mathrm{hr})$ & $1.8 \pm 0.2$ & $1.7 \pm 0.2$ \\
$\mathrm{AUC}_{0-\infty}(\mathrm{ng} \cdot \mathrm{hr} / \mathrm{mL})^{\#}$ & $1816.5 \pm 206.4$ & $3308.5 \pm 486.2$ \\
\hline
\end{tabular}

${ }^{\#} P \leq 0.05$.

and axillary lymph nodes after the oral administration are shown in Figure 9(a), in which the concentrations of Ptx after the administration of Ptx-loaded S-SEDDS were significantly higher than those of the reference solution in both lymph nodes. Moreover, the lymphatic targeting efficiencies of Ptx calculated as the ratio of the lymph node concentration to the plasma concentration are shown in Figure 9(b). The Ptxloaded S-SEDDS shows higher lymphatic targeting efficiencies than those of the reference solution. In the mesenteric lymph nodes, there was a significant difference $(P \leq 0.05)$ between the Ptx-loaded S-SEDDS and reference solution. This increased lymphatic targeting efficiency can lower the drug amount required to have a clinical effect. Moreover, because of increasing efficiency at the targeted sides, the use of Ptx might reduce the systemic side effects. These results suggest that the prepared S-SEDDS containing Ptx could be used as effective oral formulation for enhancing the BA of Ptx and targeting drug delivery to the lymphatic system.

\section{Conclusions}

We have prepared S-SEDDS containing Ptx easily and reproducibly by the spray drying method for enhancing the
BA and targeted delivery of Ptx to the lymphatic system. The Ptx-loaded S-SEDDS was prepared using Aerosil 200 $(250 \mathrm{mg})$, water $(100 \mathrm{~mL})$, and Ptx-loaded liquid SEDDS $(1 \mathrm{~mL})$. The Ptx-loaded liquid SEDDS consisting of Ptx $(1 \mathrm{mg})$ and blank liquid SEDDS $(100 \mathrm{mg})$ which contains $10 \%$ oil (ethyl oleate), $80 \%$ surfactant mixture (Tween 80 : Carbitol, $90: 10, \mathrm{w} / \mathrm{w}$ ), and $10 \%$ cosolvent (PEG 400) is an optimal formulation in terms of mean emulsion droplet size, zeta potential, and encapsulation efficiency. The optimal Ptxloaded S-SEDDS formulation showed $16.9 \pm 1.53 \mathrm{~nm}, 12.47 \pm$ $1.66 \mathrm{mV}$, and $56.2 \pm 8.1 \%$ in mean emulsion droplet size, zeta potential, and encapsulation efficiency, respectively. Both DSC measurements and X-ray diffraction analysis suggested that Ptx in the S-SEDDS may be in the form of molecular dispersion in the emulsions or distributed in an amorphous state or crystalline with very small size. In vitro dissolution test showed that the prepared S-SEDDS had a dramatic increase in in vitro release rate than the powder. Furthermore, from the in vivo studies, the prepared Ptx-loaded S-SEDDS showed significant increases $(P \leq$ 0.05) in $\mathrm{AUC}_{0-\infty}, C_{\max }$, and lymphatic targeting efficiency in comparison to those of the reference solution after the oral administration. In conclusion, our research suggested that the prepared S-SEDDS formulation could be a good candidate for the enhancement of BA and delivery of Ptx to the lymphatic system, and this approach also could be used as an alternative formulation technology for other low BA drugs.

\section{Competing Interests}

The authors declare that there are no competing interests regarding the publication of this paper. 


\section{Acknowledgments}

This research was supported by the Basic Science Research Program through the National Research Foundation of Korea (NRF) funded by the Ministry of Education (2014R1A1A2056937).

\section{References}

[1] A. Henningsson, M. O. Karlsson, L. Viganò, L. Gianni, J. Verweij, and A. Sparreboom, "Mechanism-based pharmacokinetic model for paclitaxel," Journal of Clinical Oncology, vol. 19, no. 20, pp. 4065-4073, 2001.

[2] A. K. Singla, A. Garg, and D. Aggarwal, "Paclitaxel and its formulations," International Journal of Pharmaceutics, vol. 235, no. 1-2, pp. 179-192, 2002.

[3] J. Crown, M. O'Leary, and W.-S. Ooi, "Docetaxel and paclitaxel in the treatment of breast cancer: a review of clinical experience," Oncologist, vol. 9, no. 2, pp. 24-32, 2004.

[4] A. K. Nowak, N. R. C. Wilcken, M. R. Stockler, A. Hamilton, and D. Ghersi, "Systematic review of taxane-containing versus non-taxane-containing regimens for adjuvant and neoadjuvant treatment of early breast cancer," The Lancet Oncology, vol. 5, no. 6, pp. 372-380, 2004.

[5] L.-Q. Yang, B. Wang, H. Gan et al., "Enhanced oral bioavailability and anti-tumour effect of paclitaxel by 20(s)-ginsenoside Rg3 in vivo," Biopharmaceutics \& Drug Disposition, vol. 33, no. 8, pp. 425-436, 2012.

[6] S. M. Azouz, J. Walpole, S. Amirifeli, K. N. Taylor, M. W. Grinstaff, and Y. L. Colson, "Prevention of local tumor growth with paclitaxel-loaded microspheres," Journal of Thoracic and Cardiovascular Surgery, vol. 135, no. 5, pp. 1014-1021, 2008.

[7] P. H.-L. Tran, T. T.-D. Tran, and B.-J. Lee, "Biodistribution and pharmacokinetics in rats and antitumor effect in various types of tumor-bearing mice of novel self-assembled gelatin-oleic acid nanoparticles containing paclitaxel," Journal of Biomedical Nanotechnology, vol. 10, no. 1, pp. 154-165, 2014.

[8] M. R. Wenk, A. Fahr, R. Reszka, and J. Seelig, "Paclitaxel partitioning into lipid bilayers," Journal of Pharmaceutical Sciences, vol. 85, no. 2, pp. 228-231, 1996.

[9] C. M. Kearns, L. Gianni, and M. J. Egorin, "Paclitaxel pharmacokinetics and pharmacodynamics," Seminars in Oncology, vol. 22, no. 3, pp. 16-23, 1995.

[10] D. M. Vyas and J. F. Kadow, "6 Paclitaxel: a unique tubulin interacting anticancer agent," Progress in Medicinal Chemistry, vol. 32, pp. 289-337, 1995.

[11] T. Yang, F.-D. Cui, M.-K. Choi et al., "Enhanced solubility and stability of PEGylated liposomal paclitaxel: in vitro and in vivo evaluation," International Journal of Pharmaceutics, vol. 338, no. 1-2, pp. 317-326, 2007.

[12] S. J. Torne, K. A. Ansari, P. R. Vavia, F. Trotta, and R. Cavalli, "Enhanced oral paclitaxel bioavailability after administration of paclitaxel-loaded nanosponges," Drug Delivery, vol. 17, no. 6, pp. 419-425, 2010.

[13] G. J. Fetterly and R. M. Straubinger, "Pharmacokinetics of paclitaxel-containing liposomes in rats," AAPS PharmScitech, vol. 5, no. 4, 2003.

[14] Y. W. Cho, J. Lee, S. C. Lee, K. M. Huh, and K. Park, "Hydrotropic agents for study of in vitro paclitaxel release from polymeric micelles," Journal of Controlled Release, vol. 97, no. 2, pp. 249-257, 2004.
[15] H.-Y. Cho, C. K. Lee, and Y.-B. Lee, "Preparation and evaluation of PEGylated and folate-pegylated liposomes containing paclitaxel for lymphatic delivery," Journal of Nanomaterials, vol. 2015, Article ID 471283, 10 pages, 2015.

[16] K. Guo and C. C. Chu, "Biodegradable and injectable paclitaxelloaded poly(ester amide)s microspheres: fabrication and characterization," Journal of Biomedical Materials Research Part B: Applied Biomaterials, vol. 89, no. 2, pp. 491-500, 2009.

[17] S. Peltier, J.-M. Oger, F. Lagarce, W. Couet, and J.-P. Benoît, "Enhanced oral paclitaxel bioavailability after administration of paclitaxel-loaded lipid nanocapsules," Pharmaceutical Research, vol. 23, no. 6, pp. 1243-1250, 2006.

[18] D. Pandita, A. Ahuja, V. Lather et al., "Development of lipidbased nanoparticles for enhancing the oral bioavailability of paclitaxel," AAPS PharmSciTech, vol. 12, no. 2, pp. 712-722, 2011.

[19] D. Yang, S. Van, X. Jiang, and L. Yu, "Novel free paclitaxelloaded poly(L- $\gamma$-glutamylglutamine)-paclitaxel nanoparticles," International Journal of Nanomedicine, vol. 6, no. 1, pp. 85-91, 2011.

[20] V. Zabaleta, G. Ponchel, H. Salman, M. Agüeros, C. Vauthier, and J. M. Irache, "Oral administration of paclitaxel with pegylated poly(anhydride) nanoparticles: permeability and pharmacokinetic study," European Journal of Pharmaceutics and Biopharmaceutics, vol. 81, no. 3, pp. 514-523, 2012.

[21] J. Van Asperen, O. Van Tellingen, A. Sparreboom et al., "Enhanced oral bioavailability of paclitaxel in mice treated with the P-glycoprotein blocker SDZ PSC 833," British Journal of Cancer, vol. 76, no. 9, pp. 1181-1183, 1997.

[22] M. V. S. Varma and R. Panchagnula, "Enhanced oral paclitaxel absorption with vitamin E-TPGS: effect on solubility and permeability in vitro, in situ and in vivo," European Journal of Pharmaceutical Sciences, vol. 25, no. 4-5, pp. 445-453, 2005.

[23] M. Nirosha, A. Badarinath, M. Hyndavi et al., "Recent advances in self-emulsifying drug delivery system," International Journal of Review in Life Sciences, vol. 1, no. 4, pp. 206-214, 2011.

[24] K. Kohli, S. Chopra, D. Dhar, S. Arora, and R. K. Khar, "Selfemulsifying drug delivery systems: an approach to enhance oral bioavailability," Drug Discovery Today, vol. 15, no. 21-22, pp. 958-965, 2010.

[25] B. S. Jill, R. K. Akshay, M. R. Ketan et al., "Self micro emulsifying drug delivery system," International Journal of Pharmaceutical Sciences, vol. 1, pp. 13-33, 2010.

[26] J.-L. Tang, J. Sun, and Z.-G. He, "Self-emulsifying drug delivery systems: strategy for improving oral delivery of poorly soluble drugs," Current Drug Therapy, vol. 2, no. 1, pp. 85-93, 2007.

[27] H.-Y. Cho, J.-H. Choi, I.-J. Oh, and Y.-B. Lee, "Self-emulsifying drug delivery system for enhancing bioavailability and lymphatic delivery of tacrolimus," Journal of Nanoscience and Nanotechnology, vol. 15, no. 2, pp. 1831-1841, 2015.

[28] B. Mistry, M. M. Jones, P. Kubiak et al., "A phase 1 study to assess the absolute bioavailability and safety of an oral solution of decitabine in subjects with myelodysplastic syndromes (MDS)," ASH Annual Meeting Abstracts, vol. 118, no. 21, article 3801, 2011.

[29] H.-Y. Cho and Y.-B. Lee, "Nano-sized drug delivery systems for lymphatic delivery," Journal of Nanoscience and Nanotechnology, vol. 14, no. 1, pp. 868-880, 2014.

[30] G. Jurisic and M. Detmar, "Lymphatic endothelium in health and disease," Cell and Tissue Research, vol. 335, no. 1, pp. 97-108, 2009.

[31] A. F. Chambers, A. C. Groom, and I. C. MacDonald, "Dissemination and growth of cancer cells in metastatic sites," Nature Reviews Cancer, vol. 2, no. 8, pp. 563-572, 2002. 
[32] B. Tang, G. Cheng, J.-C. Gu, and C.-H. Xu, "Development of solid self-emulsifying drug delivery systems: preparation techniques and dosage forms," Drug Discovery Today, vol. 13, no. 13-14, pp. 606-612, 2008.

[33] R. P. Patel, M. P. Patel, and A. M. Suthar, "Spray drying technology: an overview," Indian Journal of Science and Technology, vol. 2, no. 10, pp. 44-47, 2009.

[34] M. Sun, J. Han, X. Guo et al., "Design, preparation and in vitro evaluation of paclitaxel-loaded self-nanoemulsifying drug delivery system," Asian Journal of Pharmaceutical Sciences, vol. 6, no. 1, pp. 18-25, 2011.

[35] Z. Wu, D. Guo, L. Deng, Y. Zhang, Q. Yang, and J. Chen, "Preparation and evaluation of a self-emulsifying drug delivery system of etoposide-phospholipid complex," Drug Development and Industrial Pharmacy, vol. 37, no. 1, pp. 103-112, 2011.

[36] M. M. Rieger and L. D. Rhein, Surfactants in Cosmetics, Marcel Dekker, New York, NY, USA, 2nd edition, 1997.

[37] ICI Americas, The HLB System: A Time-saving Guide to Emulsifier Selection, ICI Americas, Incorporated, Wilmington, Del, USA, 1984.

[38] T. Schmidts, P. Schlupp, A. Gross, D. Dobler, and F. Runkel, "Required HLB determination of some pharmaceutical oils in submicron emulsions," Journal of Dispersion Science and Technology, vol. 33, no. 6, pp. 816-820, 2012.

[39] C. W. Pouton, "Lipid formulations for oral administration of drugs: Non-emulsifying, self-emulsifying and 'selfmicroemulsifying' drug delivery systems," European Journal of Pharmaceutical Sciences, vol. 11, supplement 2, pp. S93-S98, 2000.

[40] D. Patel and K. K. Sawant, "Oral bioavailability enhancement of acyclovir by self-microemulsifying drug delivery systems (SMEDDS)," Drug Development and Industrial Pharmacy, vol. 33, no. 12, pp. 1318-1326, 2007.

[41] X. Wu, J. Xu, X. Huang, and C. Wen, "Self-microemulsifying drug delivery system improves curcumin dissolution and bioavailability," Drug Development and Industrial Pharmacy, vol. 37, no. 1, pp. 15-23, 2011.

[42] E. Moghimipour, A. Salimi, and F. Leis, "Preparation and evaluation of tretinoin microemulsion based on pseudo-ternary phase diagram," Advanced Pharmaceutical Bulletin, vol. 2, no. 2, pp. 141-147, 2012.

[43] Y.-D. Yan, J. A. Kim, M. K. Kwak, B. K. Yoo, C. S. Yong, and H.G. Choi, "Enhanced oral bioavailability of curcumin via a solid lipid-based self-emulsifying drug delivery system using a spraydrying technique," Biological and Pharmaceutical Bulletin, vol. 34, no. 8, pp. 1179-1186, 2011.

[44] T. Yi, J. Wan, H. Xu, and X. Yang, "A new solid selfmicroemulsifying formulation prepared by spray-drying to improve the oral bioavailability of poorly water soluble drugs," European Journal of Pharmaceutics and Biopharmaceutics, vol. 70, no. 2, pp. 439-444, 2008.

[45] C.-K. Lee and J.-S. Choi, "Effects of silibinin, inhibitor of CYP3A4 and P-glycoprotein in vitro, on the pharmacokinetics of paclitaxel after oral and intravenous administration in rats," Pharmacology, vol. 85, no. 6, pp. 350-356, 2010.

[46] A. Sparreboom, J. Van Asperen, U. Mayer et al., "Limited oral bioavailability and active epithelial excretion of paclitaxel (Taxol) caused by P-glycoprotein in the intestine," Proceedings of the National Academy of Sciences of the United States of America, vol. 94, no. 5, pp. 2031-2035, 1997.

[47] A. Mann, A. Thompson, N. Robbins, and A. L. Blomkalns, "Localization, identification, and excision of murine adipose depots," Journal of Visualized Experiments, no. 94, Article ID e52174, 2014.

[48] C. M. Parkinson, A. O’Brien, T. M. Albers, M. A. Simon, C. B. Clifford, and K. R. Pritchett-Corning, "Diagnostic necropsy and selected tissue and sample collection in rats and mice," Journal of Visualized Experiments, no. 54, Article ID e2966, 2011.

[49] C. L. Scudamore, A Practical Guide to the Histology of the Mouse, Wiley-Blackwell, Hoboken, NJ, USA, 2013.

[50] F. Coudoré, N. Authier, D. Guillaume, A. Béal, E. Duroux, and J. Fialip, "High-performance liquid chromatographic determination of paclitaxel in rat serum: application to a toxicokinetic study," Journal of Chromatography B: Biomedical Sciences and Applications, vol. 721, no. 2, pp. 317-320, 1999.

[51] L. He, G.-L. Wang, and Q. Zhang, "Studies on hypersensitivity and pharmacokinetics of paclitaxel microemulsion," Acta Pharmaceutica Sinica, vol. 38, no. 3, pp. 227-230, 2003.

[52] H. Mase, M. Hiraoka, A. Suzuki et al., "Determination of new anticancer drug, paclitaxel, in biological fluids by high performance liquid chromatography," Journal of the Pharmaceutical Society of Japan, vol. 114, no. 5, pp. 351-355, 1994.

[53] F. Mohamed, P. Marchettini, O. A. Stuart, and P. H. Sugarbaker, "Pharmacokinetics and tissue distribution of intraperitoneal paclitaxel with different carrier solutions," Cancer Chemotherapy and Pharmacology, vol. 52, no. 5, pp. 405-410, 2003.

[54] M. Gibaldi and D. Perrier, Pharmacokinetics, CRC Press, Boca Raton, Fla, USA, 2nd edition, 1982.

[55] J. Liu, D. Meisner, E. Kwong, X. Y. Wu, and M. R. Johnston, "Translymphatic chemotherapy by intrapleural placement of gelatin sponge containing biodegradable paclitaxel colloids controls lymphatic metastasis in lung cancer," Cancer Research, vol. 69, no. 3, pp. 1174-1181, 2009.

[56] C. W. Pouton and C. J. H. Porter, "Formulation of lipid-based delivery systems for oral administration: materials, methods and strategies," Advanced Drug Delivery Reviews, vol. 60, no. 6, pp. 625-637, 2008.

[57] M. A. Swartz, "The physiology of the lymphatic system," Advanced Drug Delivery Reviews, vol. 50, no. 1-2, pp. 3-20, 2001.

[58] R. Nankervis, S. S. Davis, N. H. Day, and P. N. Shaw, "Intestinal lymphatic transport of three retinoids in the rat after oral administration: effect of lipophilicity and lipid vehicle," International Journal of Pharmaceutics, vol. 130, no. 1, pp. 57-64, 1996.

[59] N. L. Trevaskis, W. N. Charman, and C. J. H. Porter, "Lipidbased delivery systems and intestinal lymphatic drug transport: a mechanistic update," Advanced Drug Delivery Reviews, vol. 60, no. 6, pp. 702-716, 2008.

[60] R. N. Gursoy and S. Benita, "Self-emulsifying drug delivery systems (SEDDS) for improved oral delivery of lipophilic drugs," Biomedicine and Pharmacotherapy, vol. 58, no. 3, pp. 173-182, 2004.

[61] P. J. Kadu, S. S. Kushare, D. D. Thacker, and S. G. Gattani, "Enhancement of oral bioavailability of atorvastatin calcium by self-emulsifying drug delivery systems (SEDDS)," Pharmaceutical Development and Technology, vol. 16, no. 1, pp. 65-74, 2011.

[62] P. R. Nepal, H.-K. Han, and H.-K. Choi, "Preparation and in vitro-in vivo evaluation of Witepsol ${ }^{\circledR} \mathrm{H} 35$ based selfnanoemulsifying drug delivery systems (SNEDDS) of coenzyme Q10," European Journal of Pharmaceutical Sciences, vol. 39, no. 4, pp. 224-232, 2010.

[63] S. K. Singh, P. R. P. Verma, and B. Razdan, "Development and characterization of a lovastatin-loaded self-microemulsifying drug delivery system," Pharmaceutical Development and Technology, vol. 15, no. 5, pp. 469-483, 2010. 
[64] S. N. Bhattachar, D. M. Bender, S. A. Sweetana et al., "Discovery formulations: approaches and practices in early preclinical development," in Discovering and Developing Molecules with Optimal Drug-Like Properties, A. C. Templeton, S. R. Byrn, R. J. Haskell et al., Eds., pp. 49-94, Springer, New York, NY, USA, 2015.

[65] F.-H. Yang, Q. Zhang, Q.-Y. Liang et al., "Bioavailability enhancement of paclitaxel via a novel oral drug delivery system: paclitaxel-loaded glycyrrhizic acid micelles," Molecules, vol. 20, no. 3, pp. 4337-4356, 2015.

[66] S. G. I. Choi, S.-E. Lee, B.-S. Kang, C. L. I. Ng, E. Davaa, and J.-S. Park, "Thermosensitive and mucoadhesive sol-gel composites of paclitaxel/dimethyl- $\beta$-cyclodextrin for buccal delivery," PLoS ONE, vol. 9, no. 10, Article ID e109090, 2014.

[67] J. G. Hiremath, N. S. Khamar, S. G. Palavalli, C. G. Rudani, R. Aitha, and P. Mura, "Paclitaxel loaded carrier based biodegradable polymeric implants: preparation and in vitro characterization," Saudi Pharmaceutical Journal, vol. 21, no. 1, pp. 85-91, 2013.

[68] H. Zhang, H. Hu, H. Zhang et al., "Effects of PEGylated paclitaxel nanocrystals on breast cancer and its lung metastasis," Nanoscale, vol. 7, no. 24, pp. 10790-10800, 2015. 

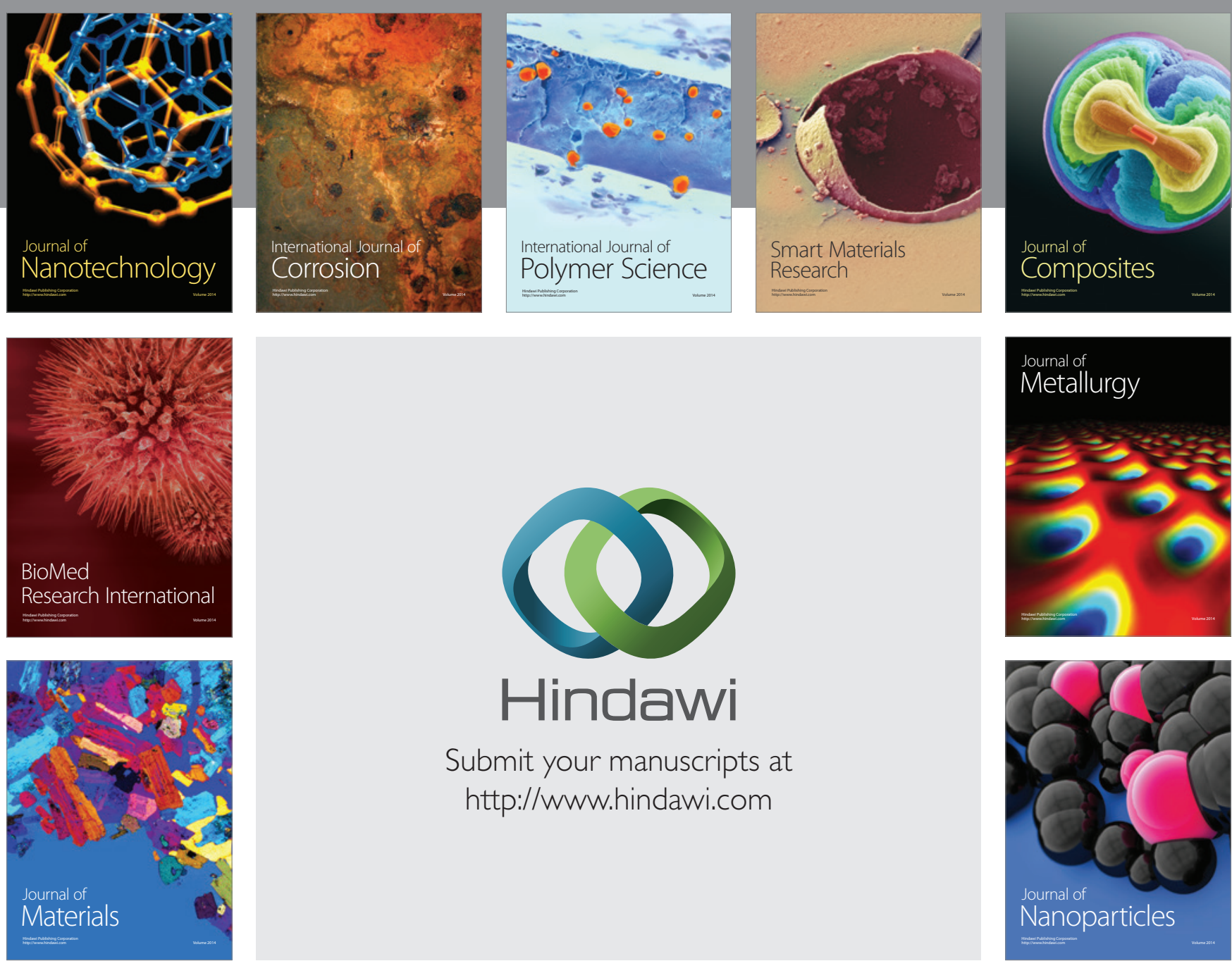

\section{Hindawi}

Submit your manuscripts at

http://www.hindawi.com

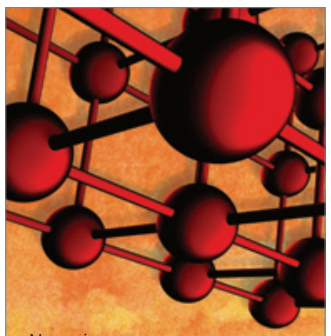

Materials Science and Engineering
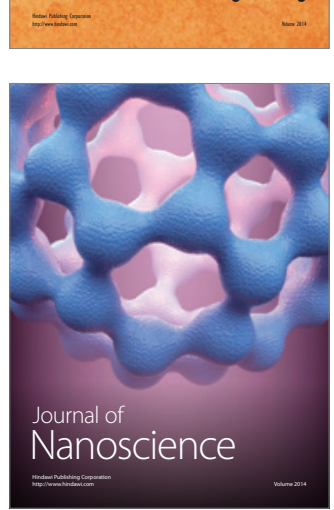
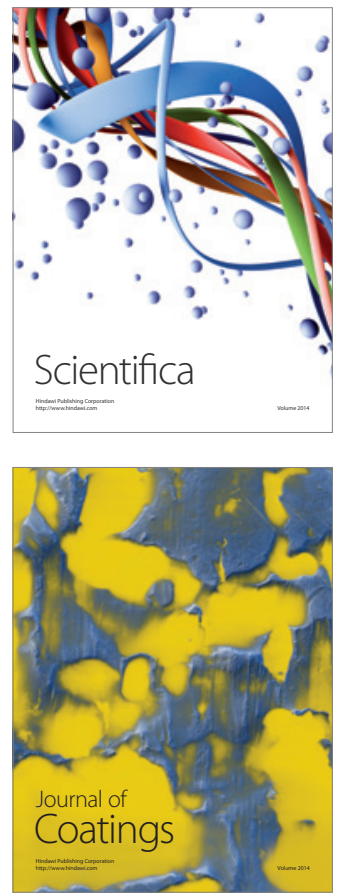
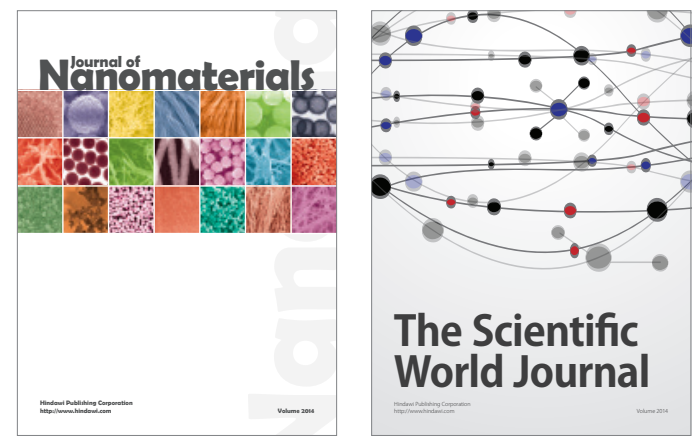

The Scientific World Journal
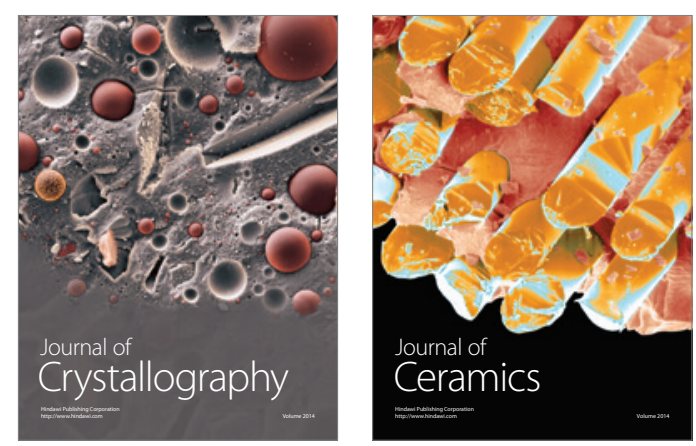
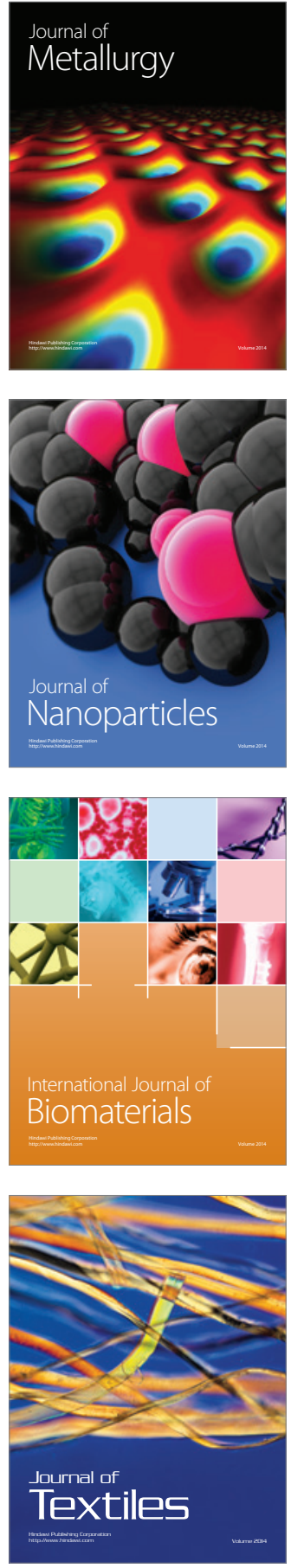